\title{
Trends in the Development of Tailored Elastin-Like Recombinamer-Based Porous Biomaterials for Soft and Hard Tissue Applications
}

\section{Lubinda Mbundi ${ }^{1,2}$, Miguel González-Pérez ${ }^{2}$, Fernando González-Pérez ${ }^{2}$, Diana Juanes-Gusano ${ }^{2}$ and José Carlos Rodríguez-Cabello ${ }^{2 *}$}

${ }^{1} \mathrm{NHS}$ Blood and Transplant (CMT), Barnsley, United Kingdom, ${ }^{2}$ BIOFORGE, CIBER-BBN, Edificio Lucia, Universidad de Valladolid, Valladolid, Spain

Porous biomaterials are of significant interest in a variety of biomedical applications as they enable the diffusion of nutrients and gases as well as the removal of metabolic waste from implants. Pores also provide 3D spaces for cell compartmentalization and the development of complex structures such as vasculature and the extracellular matrix. Given the variation in the extracellular matrix composition across and within different tissues, it is necessary to tailor the physicochemical characteristics of biomaterials and or surfaces thereof for optimal bespoke applications. In this regard, different synthetic and natural polymers have seen increased usage in the development of biomaterials and surface coatings; among them, elastin-like polypeptides and their recombinant derivatives have received increased advocacy. The modular assembly of these molecules, which can be controlled at a molecular level, presents a flexible platform for the endowment of bespoke biomaterial properties. In this review, various elastin-like recombinamer-based porous biomaterials for both soft and hard tissue applications are discussed and their current and future applications evaluated.

Keywords: porous scaffolds, elastin, tropoelastin, elastin-like polypeptides, elastin-like recombinamer

\section{INTRODUCTION}

Although the body has the ability to heal small tissue damage or loss, large and severe tissue damage due to trauma or disease remain a challenge and are associated with disability, reduced quality of life, and in some cases, death (Krafts, 2010). To address this, medical interventions popularly employ implants and grafts of xenogeneic, allogeneic, and autologous origin, with the latter being the gold standard approach. However, the respective limitations such as the risk of disease and immune rejection, shortage of donor tissue, and donor site morbidity have led to increased advocacy for alternative approaches. In this regard, a plethora of biomaterials have been produced for different tissue engineering applications and continue to be developed further (Jones et al., 2002; Hing et al., 2005; Zhou et al., 2013; Shahrokhi et al., 2014; Wong et al., 2015; Sheikh et al., 2017; Mastroianni et al., 2018). The materials commonly used to produce biomaterials include metals, ceramics, polymers (synthetic and natural polymers), and composites (a mixture of two or more types) (Hench, 1998; Detsch et al., 2018).

Regardless of the type of material used, it is well accepted that an ideal biomaterial needs to be biocompatible, support cell attachment and viability, and curtail unwanted host immune response in vivo (Bačáková et al., 2014); be bioactive and endow desired physicochemical cues for cellular activities 
necessary to regenerate tissue (e.g., differentiation and proliferation) (Tsiapalis et al., 2017; Najdanović et al., 2018); possess appropriate mechanical properties to provide a suitable local environment for cells and regenerating tissue (Mitragotri and Lahann, 2009; Lin et al., 2011); and have tunable biodegradation that allows the material to sustain physiological load as it is being replaced by regenerating tissue (Cima et al., 1991; Kweon et al., 2003; Guarino and Ambrosio, 2014; Raeisdasteh Hokmabad et al., 2017; Song et al., 2018). To meet these requirements, especially for bulk materials, biomaterials need to allow cell infiltration, migration, and integration that support the in situ development of complex structures such as blood vessels and innervation (Mitrousis et al., 2018). Crucial to this is the unimpeded diffusion of gases (e.g., oxygen) and biomolecules (e.g., nutrients and signaling molecules), as well as waste removal. Indeed, where there is no intrinsic capillary network, the maximal thickness engineered tissue can remain functional before viable cells are affected by the lack of oxygen within the deeper compartments of the biomaterial, which is reported to be approximately 150-200 $\mu \mathrm{m}$ (Christina et al., 2005).

To address this, porous scaffolds with varying degree of pore interconnectivity have received increased advocacy, which is evident in the many different methods that exist for the production of porous materials. Given the heterogeneity of the extracellular matrix (ECM) within and across different tissues and organs, the biomaterial design needs to be controlled and tailored to both recapitulate the local cell environment and meet the intended application (i.e., tissue or organ function). However, most polymers (synthetic and natural), ceramics, and metals have a predetermined structure and are limited in the degree to which they can be functionalized (Acosta et al., 2020). In light of these limitations, recombinant protein technologies (i.e., recombinant collagen, silk, and elastin proteins) have received increased attention as they allow for a higher degree of control into the chemical makeup and structure of the materials owing to their modular design that allows structural control at a molecular level. In this regard, elastin-like polypeptide (ELP), and in particular their recombinant derivatives, the elastin-like recombinamers (ELRs), and biomaterials thereof have gained popularity due to the unique biochemical and mechanical properties associated with elastin (Ibáñez-Fonseca et al., 2019).

In this review, we provide an overview of porous biomaterials and methods of production thereof and highlight how scaffold pores and porosity are explored to improve the functional outcome of cells in $3 \mathrm{D}$ culture and engraftment. The objective is not to provide a comprehensive list of all porous biomaterials reported in the literature but rather to conceptualize the different strategies, highlighting key examples with focus on biomaterials made wholly or in part with elastin or ELRs and ELR polymers. Trends in ELR-based porous biomaterials and strategies used to control ELR porosity and bioactivity in soft and hard tissue applications are also explored.

\section{POROUS BIOMATERIALS}

\section{Physical and Biological Qualities}

Generally, tissue engineering approaches use natural and or artificial supports (i.e., cell scaffolds, hip implants, and stents) with or without cells to produce two-dimensional (2D) or threedimensional (3D) constructs with the aim of structurally, mechanically, and functionally recapitulating normal tissue. To achieve this, one of the key tissue engineering approaches involves the design and use of porous scaffolds that can provide cells with physiological surroundings suitable for efficient tissue regeneration (Bonfield, 2005; Karageorgiou and Kaplan, 2005; Eisenbarth, 2007). In addition to qualities such as mechanical function, structural integrity, support for nutrient and growth factor supply, cellular invasion and mass transport (for permeability and diffusion) (Hollister, 2005), pore size, and orientation, the overall porosity of the scaffold is crucial for tissue regeneration as it affects cell infiltration and proliferation, vascularization, innervation, and nutrient diffusion.

Generally, scaffold pores are classed as micropores $(\leq 2 \mathrm{~nm})$, mesopores $(2-50 \mathrm{~nm})$, and macropores (>50 nm) (McNaught and Wilkinson, 1997; McCusker et al., 2003; Borislav et al., 2007). Microporous and mesoporous materials are mainly explored for their adsorptive properties (e.g., micro- and mesoporous carbon-based materials used in water remediation) (Busquets et al., 2016) and find less usage in biomedical applications due to ultrasmall pore size. Macroporous materials on the other hand, owing to their large pore size and the fact that a wide range of polymers (i.e., natural and synthetic) can be used to make them, are widely used in biomedical applications. However, it is important to note that although large pore size of scaffolds can allow effective nutrient supply, gas diffusion, and metabolic waste removal, they can potentially lead to low cell attachment and reduced intracellular signaling, while small pore-sized scaffolds can do the opposite (Oh et al., 2007; Annabi, 2012). However, since this is dependent on the type of cells and materials used, the decision as to whether to produce scaffolds containing larger or smaller pores (i.e., pore size $>$ or $<50 \mu \mathrm{m}$ ) or both should be informed by the intended biomedical application, particularly target cell and tissue type. Indeed, several studies have shown that there is variation in the range of optimum pore size and porosity ideal for different cells and tissues. For instance, while the optimal pore size and size range for neovascularization, fibroblasts ingrowth, and hepatocyte ingrowth is reported to be $5 \mu \mathrm{m}, 5-15$ and $20 \mu \mathrm{m}$, respectively (Gorth and Webster, 2011; Annabi, 2012), larger optimal pore size and porosity ranges have been reported for adult mammalian skin regeneration $(20-125 \mu \mathrm{m})$, chondrocyte ingrowth $(70-120 \mu \mathrm{m})$, osteoid ingrowth $(100-350 \mu \mathrm{m})$, bone formation $(290-310 \mu \mathrm{m})$, and bladder smooth muscle cell attachment and growth $(100-300 \mu \mathrm{m})$. However, the fact that the optimal pore size for processes such as liver tissue regeneration $(45-150 \mu \mathrm{m})$ is different from that for hepatocyte ingrowth, and that for vascular smooth muscle cell binding $(60-150 \mu \mathrm{m})$ and fibroblast growth is different from that for neovascularization and fibrovascular tissue ingrowth $(>500 \mu \mathrm{m})$ (Whang et al., 1999; Nasim et al., 2010; Gorth and Webster, 2011; Annabi, 2012), suggests that there is need for scaffold pore architecture to adapt suitably with regenerating tissue. In addition, the size of the pores and porosity have been shown to affect different cellular activities, including scaffold infiltration and ECM production. In one study, while an increase in pore size 


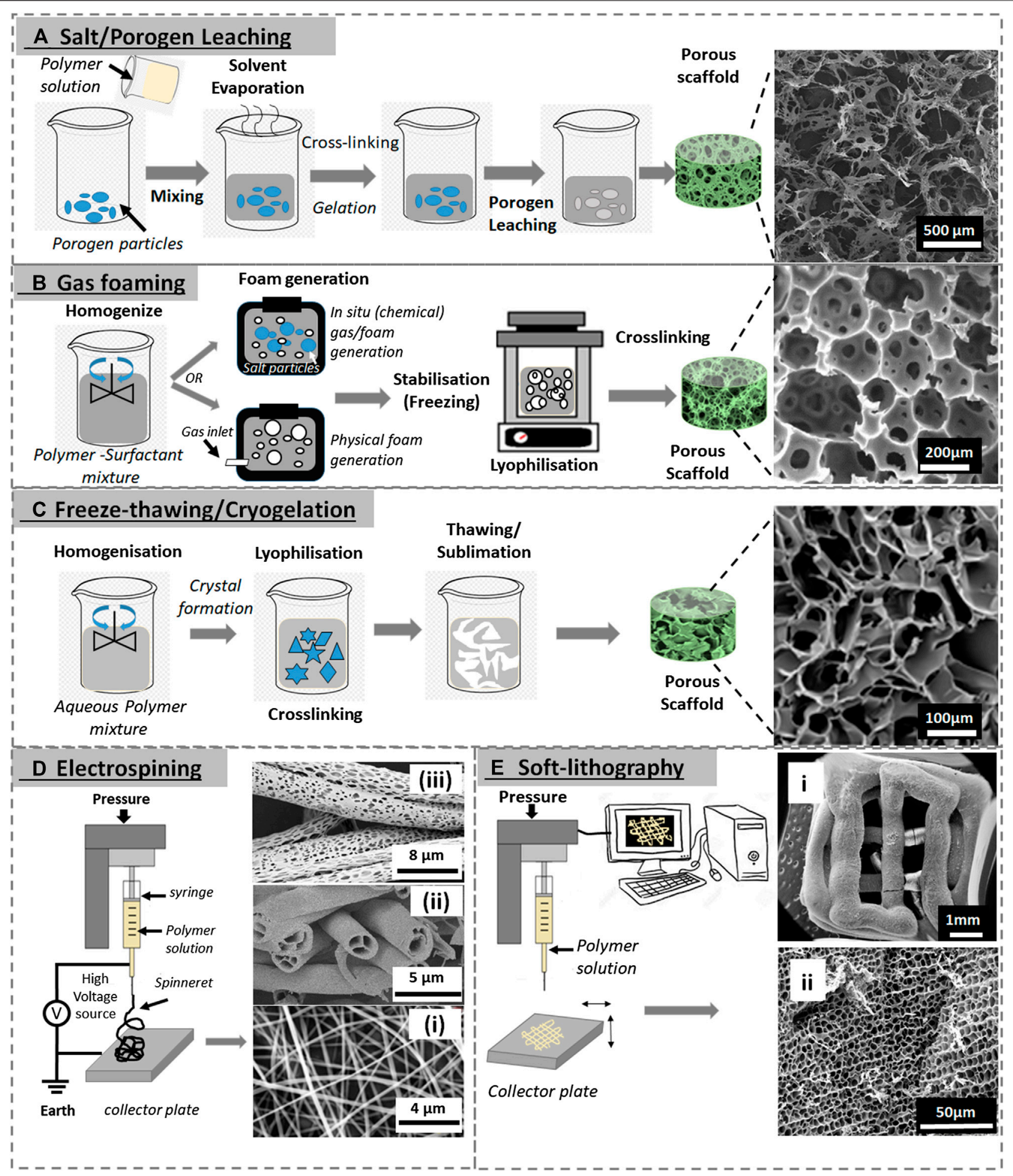

FIGURE 1 | Various porous scaffold fabrication techniques. (A) Porogen leaching (SEM image reproduced with permission from Yao et al. (2012), copyright 2012, American Chemical Society). (B) Gas foaming (SEM image reproduced with permission from Colosi et al. (2013), copyright 2013, American Chemical Society). (C) Freeze-thawing (SEM image reproduced with permission from Elowsson et al. (2013), copyright 2013, The Royal Society of Chemistry). (D) Solution electrospinning: i) SEM images of electrospun ELR fibers (mat), reproduced with permission from Putzu et al. (2016), copyright IOP Publishing; ii) hollow electrospun fibers adapted with permission from Zhao et al. (2007) copyright 2007, American Chemical Society; and iii) porous electrospun fibers adapted with permission from Katsogiannis et al. (2016), copyright John Wiley and Sons. (E) Soft lithography (3D printing): i) and ii) whole 3D-printed scaffold and ii) an SEM image of its internal porous structure, both are reproduced with permission from Salinas-Fernández et al. (2020), copyright 2020, Elsevier). 
of genipin-cross-linked gelatin hydrogels led to an increase in cell proliferation and ECM secretion (by cells), smaller pores presented increased proliferation only, even to overconfluence, without ECM secretion, during the middle and late stages of differentiation (Annabi, 2012). Elsewhere, higher porosity was shown to enhance the extent of osteogenesis and bone regeneration in vivo (Roy et al., 2003). In this work, a composite of polylactic-co-glycolic acid (PLGA) polymer with $20 \% \mathrm{w} / \mathrm{w} \beta$-tricalcium phosphate $(\beta$-TCP) ceramic engineered with macroscopic channels with a controlled pore size $(16-32 \mu \mathrm{m})$ and porosity gradient $(80-88 \%)$ showed more tissue ingrowth and new bone formation occurring in areas with higher porosity after implantation in rabbit craniums (Roy et al., 2003). Moreover, it is well established that poor or absence of pore interconnectivity results in poor nutrient and oxygen delivery as well as limited metabolic waste removal from the scaffold or graft, which can subsequently inhibit cell migration and growth within the biomaterial even if it is highly porous (Yang et al., 2001; Murphy et al., 2002). As a result, different methods have been developed for the fabrication of porous materials that allow pore size and porosity control for a variety of polymer types and target applications. As such, biocompatibility of the porous scaffold should not be generally assumed as it can vary according to the physical and chemical properties of the polymer used and the resulting scaffold. A synopsis of the methods commonly used in the production of ELR- and or elastin-like protein (ELP)-based porous biomaterials is hereinafter provided.

\section{Fabrication Techniques of Porous Scaffolds}

Given the importance of microscale morphological features within a scaffold in controlling several aspects of cell behavior such as orientation, migration, aggregation, differentiation, and ECM production, controlling scaffold porosity and pore microarchitecture features is vital in regulating tissue regeneration (Swanson and Ma, 2020). Several techniques have been developed to produce and control overall porosity, with the most common ones being solvent phase separation, casting/ porogen leaching, gas forming, electrospinning, cryogelation, soft lithography sintering, and bioextrusion (Nasim et al., 2010; Annabi, 2012). These techniques can be used on their own or as a combination of two or more to control-specific pore features and or overall microarchitecture of the scaffold so as to improve and control biointegration with host tissue (Eisenbarth, 2007; Nasim et al., 2010). Using these methods, size, shape, and orientation of the pores, porous volume and pore interconnectivity can be directly controlled and tailored for bespoke applications (Karageorgiou and Kaplan, 2005; Sabino et al., 2017; Rey and St-Pierre, 2019). A list of methods commonly used to produce porous natural polymer-based scaffold is illustrated in Figure 1, and a synopsis of how pore size and porosity have been imparted and controlled in elastin and elastin-like polymer-based biomaterials is summarized in Table 1.

\section{Solvent Casting and Porogen Leaching}

This technique involves mixing insoluble porogen particles such as salt (Liang et al., 2018; Abbasi et al., 2020), sugar (Hu et al.,
2013), gelatin (Gong et al., 2008), and paraffin (Draghi et al., 2005) particles with predetermined size in a polymer solution. The porogen particles are selected for their stability and/or insolubility in the polymer solution. Using an appropriate technique (i.e., membrane-assisted evaporation), the mixture is then solidified and the porogen particles (solute) subsequently leached or dissolved away from the structure by immersion in an appropriate solvent, leaving behind a porous network within the remaining scaffold (Nasim et al., 2010). The choice of the porogen dictates the size, shape, and uniformity of the pores within the structure, while the concentration of added porogen in the suspension determines the porosity and, to some extent, the degree of interconnectivity between the pores (Hollister, 2005; Annabi, 2012; Memic et al., 2019).

Several ELR-based porous scaffolds have been produced by using the porogen leaching method (Fu et al., 2009; FernándezColino et al., 2018). Recently, ELR polymers VKVx24 (structural and nonbioactive) and HRGD6 (contains cell adhesion RGD) were cross-linked by click chemistry and preloaded $\mathrm{NaHCO}_{3}$ porogen (sizes used: $<40,<100$, and $40-100 \mu \mathrm{m}$ ) leached out to produce porous scaffolds (Fernández-Colino et al., 2018). However, the resulting scaffold pore sizes $(24.3,38.0$, and $58.6 \mu \mathrm{m})$ were noted to be significantly smaller than their respective porogens, due in part to the scaffolds retaining the elastic properties $(2-4 \mathrm{kPa})$ of the ELR (Fernández-Colino et al., 2018). Nonetheless, these pores supported smooth muscle cell viability and infiltration and are consistent with established findings that this pore size range is ideal for fibroblastic cells (Whang et al., 1999; Nasim et al., 2010; Gorth and Webster, 2011; Lee et al., 2011; Annabi, 2012). However, the pores produced by porogen leaching using different polymers (i.e., gelatin, poly-Llactic acid (PLLA) or poly-DL-lactic-glycolic acid (PLGA), and ELR) have been reported to have poor interconnectivity, which can potentially affect the movements of cells, nutrients, and metabolic waste (Nasim et al., 2010). This limitation is widely solved by combining porogen leaching with other techniques such as gas foaming. Indeed, the lack of pore interconnectivity and pore concentration around a skin-like outer layer (away from the center) in an ELR scaffold prepared by salt leaching using $\mathrm{NaCl}$ porogen was solved by combining salt leaching and gas foaming methods by swapping $\mathrm{NaCl}$ with $\mathrm{NaHCO}_{3}$ particles, which can serve as both a porogen and gas-forming agent to produce a biocompatible scaffold with homogenously distributed and interconnected pores ranging in size from $208.6 \pm 33.5$ to $318.7 \pm 60.3 \mu \mathrm{m}$ (Fu et al., 2009). Although varying the size of the porogen can regulate the resulting scaffold pore size, varying hydrogel temperature and salt/polymer ratio has been shown to affect porosity. Indeed, increasing the temperature used to form the scaffold from $4^{\circ} \mathrm{C}$ to above ELR $T_{t}\left(37^{\circ} \mathrm{C}\right)$ has been reported to reduce pore size by $30 \%$ as well as scaffold porosity from $65 \%$ to $51 \%$, due to swelling resulting from the phase transition. Moreover, salt/polymer ratios of 0:1, 10:1, and 20:1 reported respective porosities of 50,65 , and $75 \%\left(\right.$ at $4^{\circ} \mathrm{C}$ ) and 30,50 , and $72 \%$ (at $37^{\circ} \mathrm{C}$ ) (Martín et al., 2009a). In addition to the salt/ polymer weight ratio and temperature, other processing parameters such as saturation pressure, depressurization rates, and soaking time have been used to control pore size and porosity 
TABLE 1 | Representative examples of the production and parameter control of elastin and elastin-like polypeptide-based porous scaffolds.

\begin{tabular}{|c|c|}
\hline Method & Polymer \\
\hline $\begin{array}{l}\text { Salt-leaching/gas foaming + } \\
\text { hexamethylene diisocyanate } \\
(\mathrm{HMDI}) \text { cross-linking }\end{array}$ & ELP \\
\hline Salt-leaching/gas foaming & ELR \\
\hline $\begin{array}{l}\text { Salt-leaching/gas foaming/(high } \\
\left.\text { pressure } \mathrm{CO}_{2}\right)+ \text { glutaraldehyde } \\
\text { (GA) cross-linking }\end{array}$ & $\begin{array}{l}\text { Polycaprolactone (PCL)/ } \\
\text { elastin composites }\end{array}$ \\
\hline $\begin{array}{l}\text { Salt-leaching/gas foaming/(high } \\
\left.\text { pressure } \mathrm{CO}_{2}\right)+ \text { glutaraldehyde } \\
\text { (GA) cross-linking }\end{array}$ & $\alpha$-Elastin \\
\hline $\begin{array}{l}\text { Salt-leaching/gas foaming/(high } \\
\left.\text { pressure } \mathrm{CO}_{2}\right)+ \text { Hexamethylene } \\
\text { diisocyanate (HMDI) cross- } \\
\text { linking }\end{array}$ & $\alpha$-Elastin \\
\hline $\begin{array}{l}\text { Salt-leaching/gas foaming/(high } \\
\left.\text { pressure } \mathrm{CO}_{2}\right)+ \text { glutaraldehyde } \\
\text { (GA) cross-linking }\end{array}$ & $\begin{array}{l}\text { Recombinant tropoelastin } \\
(r-T E) / \alpha \text {-elastin hybrid }\end{array}$ \\
\hline $\begin{array}{l}\text { Electrospinning + glutaraldehyde } \\
\text { (GA) cross-linking }\end{array}$ & $\begin{array}{l}\text { Human recombinant } \\
\text { tropoelastin (rh-TE) }\end{array}$ \\
\hline
\end{tabular}

Electrospinning + glutaraldehyde Collagen/elastin/PCL (GA) cross-linking

Electrospinning

Freeze drying + carbodiimide cross-linking

Casting + Molding + freeze

drying + genipin cross-linking

Gas foaming with high pressure $\mathrm{CO}_{2}+$ glutaraldehyde (GA)

cross-linking

Coacervation +

bis(sulfosuccinimidyl)suberate

(BS3) cross-linking

Coacervation +

bis(sulfosuccinimidyl)suberate

(BS3) cross-linking

Physical cross-linking

Photocross-linking

$$
\text { ELR }
$$

Photocross-linking

GO nanoparticles/
PLGA/gelatin/elastin

Pores: 24.3, 38.0, and

$58.6 \mu \mathrm{m}$, porogens $<40,<100$ and 40-100 $\mu \mathrm{m}$, respectively)

Pore size $158-545 \mu \mathrm{m}$

Pressure-dependent $14.3 \mu \mathrm{m}$ (1 bar); 4.9 um (60 bar)

Pressure-dependent: $3.9 \mu \mathrm{m}$ (1 bar); $79.8 \mu \mathrm{m}$ (60 bar)

Range $(11 \pm 2$ to $78 \pm 17 \mu \mathrm{m})$

Electrospinning (flow) rate depended: (At 1 and $3 \mathrm{ml} / \mathrm{h}$ ), pore size (1.6-21.3 and 4.0$27.9 \mu \mathrm{m})$

Polymer concentration ratio (collagen:elastin:PCL) depended: $8.64 \mu \mathrm{m}$ (5:2.5:1); $14.51 \mu \mathrm{m}(10: 5: 1)$; and 39.06 $\mu \mathrm{m}$ (10:5:10) Varying PGE blending varied pore area in the range $0.6-4.7 \mu \mathrm{m}^{2}$

Collagen/elastin

130-300 $\mu \mathrm{m}$

Silk fibroin (SF)/elastin

Pore present

Rh-TE/synthetic human elastin

Rh-TE

Rh-TE/

glycosaminoglycans (GAGs) (heparin and dermatan) Silk-ELR (SELR)

ELR methacryloyl-substituted tropoelastin (MeTro)

\begin{tabular}{|c|c|c|}
\hline Porosity & Parameter controls & References \\
\hline $30-75 \%$ & $\begin{array}{l}\text { Porogen size and } \\
\text { concentration, raising } \\
\left.\text { temperature ( } 4 \text { to } 37^{\circ} \mathrm{C}\right) \text {, } \\
\text { decreasing porosity. Increasing } \\
\text { the salt/polymer ratio increased } \\
\text { porosity }\end{array}$ & Martín et al. (2009a) \\
\hline- & - & $\begin{array}{l}\text { Fernández-Colino et al. } \\
\text { (2018) }\end{array}$ \\
\hline $23.1-91.2 \%$ & $\begin{array}{l}\text { Saturation pressure, } \\
\text { depressurization rate, and } \\
\text { soaking time }\end{array}$ & Annabi et al. (2011a,b) \\
\hline- & $\begin{array}{l}\text { Saturation pressure, } \\
\text { depressurization rate, and } \\
\text { soaking time }\end{array}$ & Annabi et al. (2009b) \\
\hline- & $\begin{array}{l}\text { Saturation pressure, } \\
\text { depressurization rate, and } \\
\text { soaking time }\end{array}$ & Annabi et al. (2009a) \\
\hline- & - & Annabi et al. (2010) \\
\hline $\begin{array}{l}14.5-34.4 \% \\
(1-3 \mathrm{ml} / \mathrm{h})\end{array}$ & $\begin{array}{l}\text { Increasing electrospinning } \\
\text { (flow) rate }\end{array}$ & $\begin{array}{l}\text { Rnjak-Kovacina et al. } \\
\text { (2011) }\end{array}$ \\
\hline- & Polymer concentration ratio & $\begin{array}{l}\text { Heydarkhan-Hagvall } \\
\text { et al. (2008) }\end{array}$ \\
\hline- & $\begin{array}{l}\text { Mat thickness and fiber } \\
\text { compactness }\end{array}$ & Han et al. (2011) \\
\hline $90-98 \%$ & - & $\begin{array}{l}\text { Buttafoco et al. (2006) } \\
\text { and Koens et al. (2010) }\end{array}$ \\
\hline $70-100 \%$ & $\begin{array}{l}\text { Elastin content increases } \\
\text { porosity. Cross-linking } \\
\text { decreases porosity }\end{array}$ & Vasconcelos et al. (2012) \\
\hline- & $\begin{array}{l}\text { Atmospheric and high } \\
\text { pressure } \mathrm{CO}_{2}\end{array}$ & Annabi et al. (2010) \\
\hline- & - & Mithieux et al. (2004) \\
\hline- & $\begin{array}{l}\text { GAGs addition increased } \\
\text { porosity }\end{array}$ & Tu et al. (2010) \\
\hline- & - & $\begin{array}{l}\text { lbáñez-Fonseca et al. } \\
\text { (2020a) }\end{array}$ \\
\hline- & $\begin{array}{l}\text { Increasing ELR concentration } \\
\text { reduced pore size and porosity }\end{array}$ & Zhang et al. (2015) \\
\hline - & $\begin{array}{l}\text { Amount of cross-linking } \\
\text { domains polymer mixture } \\
\text { (ratios) }\end{array}$ & Annabi et al. (2016) \\
\hline
\end{tabular}

(Continued on following page) 
TABLE 1 | (Continued) Representative examples of the production and parameter control of elastin and elastin-like polypeptide-based porous scaffolds.

\begin{tabular}{|c|c|c|c|c|c|}
\hline Method & Polymer & Pore size & Porosity & Parameter controls & References \\
\hline $\begin{array}{l}\text { Micropatterned } \\
\text { (polydimethylsiloxane (PDMS) } \\
\text { substrates) + SPAAC cross- } \\
\text { linked }\end{array}$ & ELR (hydrogels) & $\begin{array}{l}\text { Increasing polymer } \\
\text { concentration reduces pore } \\
\text { size: } 25 \mathrm{mg} / \mathrm{ml}(3.3 \pm 0.7 \boldsymbol{\mu m}) \text {; } \\
50 \mathrm{mg} / \mathrm{ml}(2.7 \pm 0.3 \boldsymbol{\mu m}) ; \\
100 \mathrm{mg} / \mathrm{ml}(2.4 \pm 0.3 \boldsymbol{\mu m}) ; \text { and } \\
125 \mathrm{mg} / \mathrm{ml}(1.7 \pm 0.4 \boldsymbol{\mu m})\end{array}$ & $\begin{array}{l}70-75 \%\left(4^{\circ} \mathrm{C}\right. \\
50 \mathrm{mg} / \mathrm{ml} \mathrm{ELR}\end{array}$ & $\begin{array}{l}\text { Temperature and polymer } \\
\text { concentration tuned porosity }\end{array}$ & Testera et al. (2015) \\
\hline $\begin{array}{l}\text { Solvent casting + carbodiimide } \\
\text { cross-linking }\end{array}$ & $\begin{array}{l}\text { Alginate/elastin/PEG } \\
\text { composite }\end{array}$ & $\begin{array}{l}35-45 \boldsymbol{\mu m} \text { (however, their } \\
\text { ultrastructure had bigger pore } \\
\text { structures than their surface, } \\
60-75 \boldsymbol{\mu m} \text { ) }\end{array}$ & - & - & Chandy et al. (2003) \\
\hline $\begin{array}{l}\text { Polyelectrolite layer-by-layer } \\
\text { membrane + hydrophobic and } \\
\text { electrostatic interaction }\end{array}$ & ELR & $200 \mathrm{~nm}$ & - & Number of layers & Paoli et al. (2020) \\
\hline $\begin{array}{l}\text { Liquid-liquid interface + SPAAC } \\
\text { cross-linked }\end{array}$ & ELR & $\begin{array}{l}\text { ELR concentration } 5-50 \text { mg/ } \\
\mathrm{ml} \text {, pore size } 5-2 \mu \mathrm{m} \text {, } \\
\text { respectively }\end{array}$ & - & $\begin{array}{l}\text { Increasing ELR concentration } \\
\text { reduced pore size }\end{array}$ & $\begin{array}{l}\text { González-Pérez et al. } \\
\text { (2020) }\end{array}$ \\
\hline
\end{tabular}

(Annabi et al., 2011b). Indeed, pore size and porosity characteristics can be further fine-tuned by adjusting different physicochemical parameters and features of ELRs.

\section{Cryogelation}

Cryogelation gelation (freeze-thawing) is similar in principle to the salt leaching method as they both involve the stabilization of the polymer matrix around the solid particles that are removed later to leave pores (Henderson et al., 2013; Memic et al., 2019). In cryogelation, monomers and or polymers premixed in an aqueous solvent are incubated at subzero temperatures (e.g., $-11^{\circ} \mathrm{C}$ ) followed by the elimination of formed solvent crystals (e.g., ice crystals in case of aqueous media) by thawing to produce polymer-based sponge-like micro-/supermacroporous elastic scaffolds (Henderson et al., 2013). The ice crystals that form during cryogelation or cryotropic gelation also provide surfaces (eventual pore walls) on which the cross-linking reactions of cryoconcentrated monomers in nonfrozen phase take place around the ice crystals (Gun'ko et al., 2013; Henderson et al., 2013). Since ice crystals act as porogens, their formation needs to happen before polymerization (Savina et al., 2016), and the porosity of the resulting cryogels is typically around 90-95\% of the material with microchannel ranging from 1 to $300 \mu \mathrm{m}$ (Gun'ko et al., 2013; Savina et al., 2016) and pore walls of several micrometres in thickness (Gun'ko et al., 2013). The organized fractal nature of ice crystal formation within the prepolymer solution at subzero temperature, which is affected by the freezing rate and amount of water, leads to the formation of interconnected macrostructures of the resulting cryogels (Memic et al., 2019). The simplicity of this technique, requiring only single freeze-thawing cycle, typically takes $30 \mathrm{~min}$ to sufficiently produce a structure with interconnected pores (Savina et al., 2016), and the fact that many different polymers can be used to make the scaffolds has made cryogelation an attractive alternative in the production of porous biomaterials. Indeed, natural monomers/polymers such as chitosan, gelatin, casein, elastin, and synthetic polymers such as acrylamide, polyvinyl alcohol, and poly (2-hydroxyethyl methacrylate-polyethylene glycol (HEMA) are widely used in the production of cryogels for various applications which include tissue engineering (Jurga et al., 2011; Kim et al., 2018; Memic et al., 2019), development of bioreactors (Jain et al., 2011; Jain and Kumar, 2013), apheresis (Nosé et al., 2000; Akande et al., 2015; Ingavle et al., 2018), and as water treatment filters (Busquets et al., 2016; Berillo et al., 2019).

Cryogelation retains the advantages of salt/porogen leaching fabrication methods (i.e., associated macroporosity) while overcoming associated limitations such as poor pore connectivity and the need to remove salt/porogens (Memic et al., 2019). Moreover, cryogelation can be fine-tuned by controlling parameters such as ice crystal formation, the moment and duration of polymerization (i.e., prefreezing monomer solution prior to addition of initiator or crosslinker), and concentration of initiator. Indeed, this has been used to produce scaffolds with near-uniform porosity across the material and increased the compressive modulus from 6 to $12 \mathrm{kPa}$, of the biomaterial with pore volumes and surface areas of $9 \mathrm{cc} / \mathrm{ml}$ of $\sim 0.5 \mathrm{~m}^{2} / \mathrm{g}$, respectively (Savina et al., 2016).

\section{Gas Foaming}

This technique involves the nucleation and growth of gas bubbles within a polymeric sample to produce a porous scaffold. The gas bubbles are generated either by a reactive foaming agent such as carbonates and nitrites (e.g., sodium bicarbonate producing $\mathrm{CO}_{2}$, ammonium bicarbonate producing $\mathrm{CO}_{2}$ and $\mathrm{NH}_{3}$, and sodium nitrite producing $\mathrm{N}_{2}$ ) through a chemical reaction in situ or are released from a presaturated gas-polymer mixture (Barbetta et al., 2009; Nasim et al., 2010; Dehghani and Annabi, 2011). The choice of foaming agents to be used is normally informed by cost, safety, and the nature of generated or remaining by-products postfabrication. Alternatively, inert gasses (i.e., argon or nitrogen) may be bubbled into the mixture, and the resulting pores arrested by freezing-drying and the pores can be further stabilized by cross-linking (Dehghani and Annabi, 2011). Generally, there are three steps to this gas-foaming method: 1) plasticization of the polymer by $\mathrm{CO}_{2}$ diffusion in the polymer solution at high 
pressure, 2) nucleation of gas bubbles due to depressurization and supersaturation, and 3) the growth of gas bubbles resulting from the diffusion of gas from the surrounding polymer.

While this approach avoids the use of organic solvents and has been used to produce wide ranging porosities and pore sizes (i.e., 5-600 $\mu \mathrm{m}$ ) with different polymers (Dehghani and Annabi, 2011), gas-foaming presents drawbacks such as poor pore interconnectivity, poor control over pore volume, and formation of nonporous eternal skin layer resulting from rheological and processing limitations (Barbetta et al., 2010; Dehghani and Annabi, 2011; Memic et al., 2019). These drawbacks are normally resolved by using gas-foaming techniques with other techniques such as the porogen leaching method to create interconnecting channels within the scaffold as indicated above (Dehghani and Annabi, 2011; Fernández-Colino et al., 2018).

\section{Phase Separation}

Phase separation methods are one of the most common and versatile techniques used in porous scaffold generating and is reviewed in detail elsewhere (Akbarzadeh and Yousefi, 2014). In brief, the methods involve the separating of a polymer-rich phase from a polymer-lean phase in an initially homogenous polymer system consisting of a polymer $(p)$ in a solvent $(S)$ (Figoli, 2016). There are several ways of altering the miscibility of the P/S system to attain phase separation. In one of the most common approaches, thermally induced phase separation (TIPS), polymer solubility is commonly reduced by either freezing the polymer out of solution (solid-liquid phase separation) followed by sublimations (i.e., lyophilization) to collect a porous scaffold or by lowering the temperature of the system (liquid-liquid phase separations). In the later, a polymer may be placed in a solution in which it only dissolves at a temperature close to the polymer melting point but not at a different temperature (e.g., room temperature) and then phase separation achieved by decreasing the temperature. The subsequent removal of the solvent leaves behind a solid structure in polymer-rich areas and homogenous interconnected pores in the polymer-lean areas (Annabi, 2012). This method is especially well suitable for the production of ELR-based porous scaffold due to low sequence complexity, elastic properties resulting from their intrinsic disorder, and selective solution condition (i.e., $\mathrm{pH}$, temperature, and pressure)-dependent phase separation behavior of ELRs (Ibáñez-Fonseca et al., 2019). In temperature-induced inverse temperature phase transition, ELRs are soluble in aqueous solution below their transition temperature $\left(T_{t}\right)$ and aggregate when the solution temperature is raised above their $T_{t}$ (Betre et al., 2002). In a recent study exploring intrinsic structural order and disorder properties of the ELPs, the injection (in vivo) of partially ordered polymer designed with a $T_{t}$ at body temperature resulted in the formation of stable, porous scaffolds that rapidly integrate into surrounding tissue with minimal inflammation and a high degree of vascularization (Roberts et al., 2018). In this work, by modulating particular polymer structural composition (e.g., charge-charge interaction, hydrophobicity, and polyalanine-based helicity), porosity (void volume), and pore size could be tuned between $60 \%(\sim 3-5 \mu \mathrm{m}$ pores) and $90 \%(\sim 30-50 \mu \mathrm{m}$ pores $)$ by adjusting polymer concentration within the range of 50 to $800 \mu \mathrm{M}$ (Roberts et al., 2018).

This technique is fast and scalable, and the resulting scaffold architecture can be controlled by adjusting different process parameters, such as polymer type and concentration, solvent type and composition, quenching temperature and time, coarsening process, and incorporation of inorganic particles (Akbarzadeh and Yousefi, 2014). In addition, this method can be used with other techniques such as solvent casting and porogen leaching to enable more control and fine-tuning of scaffold microarchitecture. In a study with bovine serum, a combination of salt leaching and phase separation was used to improve scaffold pore size and porosity from $(10$ to $30 \mu \mathrm{m})$ to (100 to $150 \mu \mathrm{m})$, which also improved cell viability ( 3.5 fold) and activity in vivo compared to the scaffold produced by either method separately (Nair et al., 2010).

\section{Electrospinning}

Electrospinning involves the application of an electric field to draw out polymer fibers from an electrically charged polymer solution or molten polymer. The polymer solution is charged by a voltage, and a thin jet of the solution is drawn through the air toward the oppositely charged collector surface, usually a rotary drum or flat plate. During this process, the drawn thin polymer jet reduces in thickness as it travels through air to the collector due to drying. As such, when working with ELRs, it is important to make sure that polymer solubility and stability are maintained within the changing parameters (i.e., temperature and polymer drying). Generally, the thickness of the fibers produced ranges in size from nano- to micrometres. Indeed, fiber diameter and features such as morphology (surface or internal), porosity, and wettability can be controlled by parameters such as electrical conductivity and applied voltage, polymer solution viscosity, polymer concentration, and the distance between the polymer source (injector/extruder) and collector surface. Interfiber pore size depends on how tightly packed the fibers are and the thickness of the resulting scaffold, which can be controlled using methods such as ultrasonication, sacrificial interwoven fibers (leached out after complete electrospinning), and liquid bath collector, which lead to loose fiber packing (Nasim et al., 2010; Wu and Hong, 2016; Swanson and Ma, 2020). On the other hand, intrafiber porosity is intimately connected to the chemistry and conformational arrangement of polymers in the fiber, and it is difficult to independently control pore size/shape (Nasim et al., 2010; Swanson and Ma, 2020). Nonetheless, others have combined electrospinning with other techniques such as salt leaching, freeze-thawing (cryogenic electrospinning), and gas foaming ( Wu and Hong, 2016) to generate pores within fibers. The interfiber pore size range reported with this techniques using different polymers ranges from 2 to $8 \mu \mathrm{m}$ using a combination of electrospinning and airflow perforated mandrel methods to 10-500 $\mu \mathrm{m}$ using cryogenic electrospinning and PLA (Wu and Hong, 2016). As a technique, electrospinning is versatile with proven effectiveness for making fibers using a variety of natural and synthetic biodegradable polymers (i.e., collagen, chitosan, silk, poly(glycolic acid), poly(caprolactone), and elastin-like 
polymers). Different cell types have been shown to be viable, proliferate, and differentiate to a variety of functional phenotypes on electrospun nano- to microfibrous materials (Wu and Hong, 2016). Electrospun fibrous matrices are commonly fabricated into $2 \mathrm{D}$ sheets and meshes due the difficulties associated with fabricating complex 3D structures using this techniques (Swanson and Ma, 2020).

\section{Porosity and Microarchitecture Control by Lithography and Rapid Prototyping}

To further control and improve diffusion and movement of cells and molecules within hydrogels, a variety of other approaches widely employed include microchannel fabrication and microarchitecture tailoring. One such common approach used to improve the movement of materials involves the development of microfluidic channels within hydrogels using soft lithography micromulding, a collection of methods used to fabricate or replicate structures using "soft" elastomeric masters (e.g., stamps, molds, and conformable photomasks) (Qin et al., 2010). In brief, a photomask imprinted with a desired pattern is used in combination with a silicon wafer, coated with a photoresist (i.e., SU-8 2075 by MicroChem Co.) to a desired thickness, to create a template by UV curing. Polydimethylsiloxane (PDMS) is then poured onto the SU-8 pattern, cured, and removed to generate a PDMS mold (Nasim et al., 2010; Qin et al., 2010). The polymer of interest is then poured onto the PDMS stamp and cured, usually by UV, to produce hydrogels with desired surface channel patterns that can be made into 3D microchannels by superimposing another similarly micropatterned solid hydrogel layer on top to enclose the channels (Nasim et al., 2010; Qin et al., 2010). The resulting micropatterns and microchannels have been shown to improve cell activities such as cell viability, differentiation, and alignment within the hydrogel, with greater improvement happening closer to the perfused channels presumably because of increased nutrient exchange and favorable microsurface pattern (Bryant et al., 2007; Paul et al., 2017).

Another family of methods used in the control of hydrogel porosity and microarchitecture is rapid prototyping or solid freeform (SFF) fabrication, which use computer-aided designs to generate $3 \mathrm{D}$ structures and are well reviewed elsewhere (Leong et al., 2003; Hollister, 2005; Seol et al., 2012; Shivalkar and Singh, 2017). One common SFF fabrication method for hydrogels containing microchannels is stereolithography, a liquid-based technique that involves layer-by-layer curing of a photosensitive polymer solution. (This method is well reviewed elsewhere and readers interested in the details are directed here (Melchels et al., 2010; Li et al., 2020).) In brief, a stereolithography setup is made of a container that holds curable liquid resin (i.e., UV-curable methacrylate or SPAAC polymers), a laser source (usually UV light) that induces the polymerization and cross-linking of liquid resin, a system that permits the horizontal plane movement ( $X$ - and $Y$-directions) of laser beam, and a system that controls the vertical plane movement (Z-direction) of the fabrication platform (Li et al., 2020). In brief, a thin layer of liquid polymer on a computer-controlled stage is photopolymerized from a programmed pattern by a laser scanner located above the stage. The stage is then moved downward or the nozzle delivering the polymer solution is adjusted up for another layer of polymer to be cured on top, and the process is repeated to generate a 3D object layer-by-layer (Melchels et al., 2010; Nasim et al., 2010). Using this method, different polymers, including ELRs, have been used to produce porous scaffolds, with or without cargo cells ( $\mathrm{Li}$ et al., 2020; Salinas-Fernández et al., 2020). Others have extended this technique to generate complex shapes such as multiple bifurcated channels that could potentially serve as artificial microvasculature (Sarker et al., 2018; Noor et al., 2019) and lumen conduits to guide nerve regeneration (Johnson et al., 2015; Vijayavenkataraman et al., 2018; Jafarkhani et al., 2019). This method also affords the precise placement of components such as synthetic beads, growth factors, and cells (Sieminski et al., 2005; Nasim et al., 2010; Bittner et al., 2018; Aguilar-de-Leyva et al., 2020; Li et al., 2020). Further pore size and porosity control can be achieved by combining this approach with other methods such as salt leaching and freezethawing as well as adjusting ELR physicochemical properties.

\section{NATURAL ELASTIN AND TROPOELASTIN}

Elastin is one of the key components of the mammalian ECM where it is a dominant component of mature elastic fibers and is found in abundance in tissues such as lungs, blood vessels, ligaments, and skin, where it endows elastic recoil and resilience properties as well as maintaining structural and mechanical integrity in tissue (Wise et al., 2014; Acosta et al., 2020). Elastin regulates a range of cellular activities such as proliferation, migration, and differentiation and has also been shown to modulate the coagulation cascade (Wise et al., 2014; Yeo and Weiss, 2019; Acosta et al., 2020). These inherent qualities of elastin and its complementary functions with other fibrous proteins such as collagen in the ECM makes it an attractive polymer in adult wound healing and tissue regeneration applications (Almine et al., 2012). Although elastin is highly durable in tissue, with a longevity that can be greater than that of host organism (half-life of $\sim 70$ years), it has a very slow metabolic replacement rate, and age-related failure of elastic fibers has been linked to poor tissue regeneration (Sherratt, 2009; Acosta et al., 2020). This is in part attributed to the molecular complexity, protein size, and the multiple macromolecules and steps involved in elastin fiber assembly (Sherratt, 2009; Acosta et al., 2020). Although the production of tropoelastin, the soluble monomer of elastin, is high during the mid to late embryonic stages, it is significantly low in adulthood, and it is absent in adult wound healing, despite there being an initial increase in tropoelastin production markers at the point of injury. This is in part thought to contribute to poor wound healing characterized by scaring and contractures in adults (Rnjak-Kovacina and Weiss, 2013; Acosta et al., 2020), which is in stark contrast to fetal scar-free healing where tropoelastin is abundant (Mithieux and Weiss, 2005; Almine et al., 2012; Rnjak-Kovacina and Weiss, 2013). This quality and the intrinsic properties of elastin and tropoelastin have led to increased interest in the use of elastin and elastin-like proteins in the development of biomaterials for tissue engineering application. 


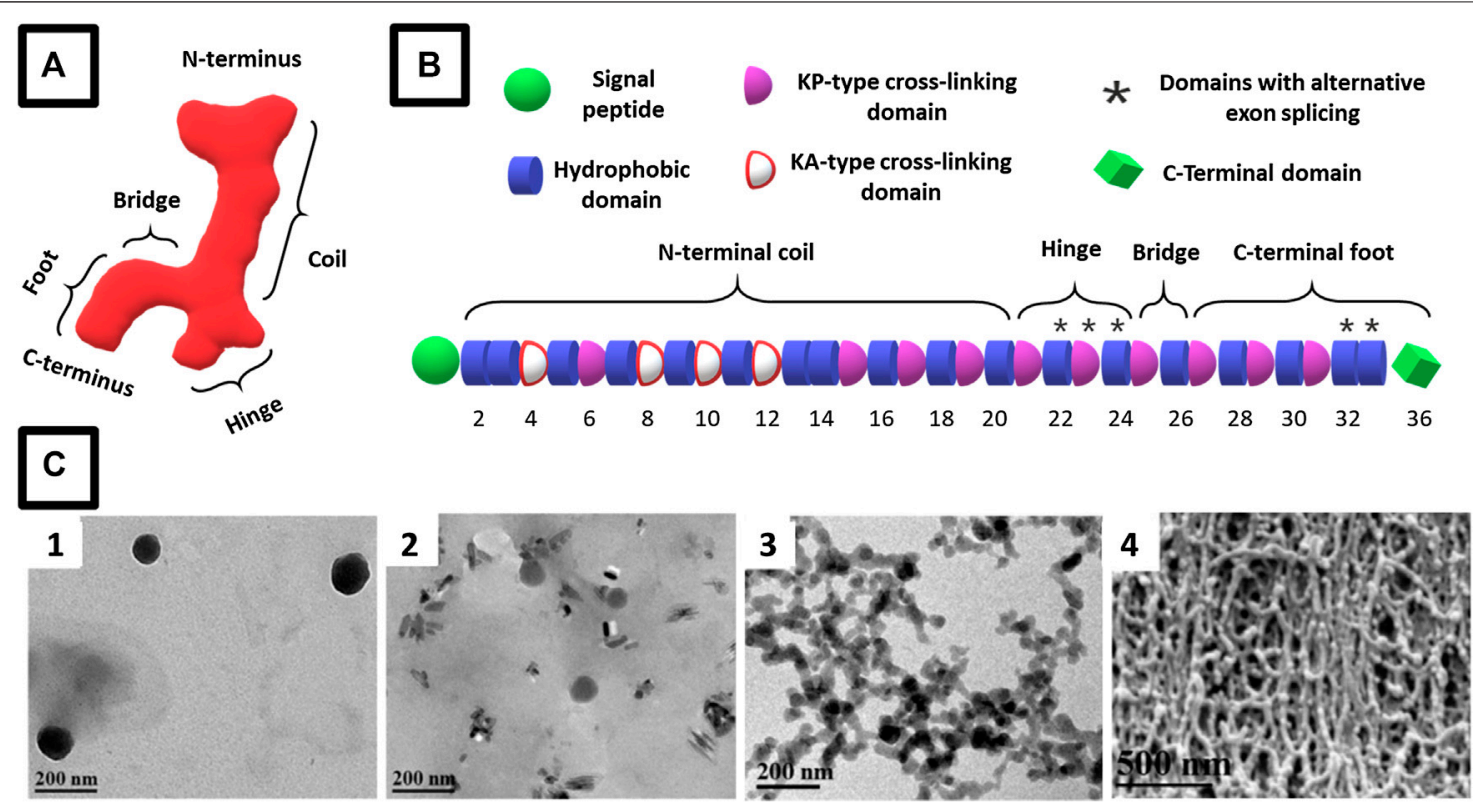

FIGURE 2 | Schematic representation of (A) the asymmetric structure of the tropoelastin monomer in solution with defined modules that include segments specialized in elasticity (coil), cell binding (C terminus), and mechanical coupling (bridge) [adapted from Mithieux et al. (2013)] and (B) representative amino acid domains arrangement in a tropoelastin monomer (adapted from (Muiznieks and Keeley (2013)). (C) Representative micrographs of the evolution of amphiphilic ELR assemblies showing typical coacervation growth from (C1) nanosized micelles at $1 \mathrm{mg} / \mathrm{ml}$ that (C-2) grow in size at $10 \mathrm{mg} / \mathrm{ml} \mathrm{and} \mathrm{(C-3)} \mathrm{aggregate} \mathrm{into} \mathrm{clusters} \mathrm{at} 50 \mathrm{mg} / \mathrm{ml}$ that eventually form self-assembled fibrils at $100 \mathrm{mg} / \mathrm{ml}$. [C $1-4$ micrographs reproduced with permission from (Misbah et al., 2015), copyright 2015, Elsevier B.V.]

\section{Tropoelastin}

Tropoelastin is a $60-$ to $72-\mathrm{kDa}$, depending on splicing and protein maturation, soluble protein secreted by elastogenic cells such as fibroblasts, endothelial cells, smooth muscle cells, chondrocytes, and keratinocytes (Figure 2A) (Yeo et al., 2011; Wise et al., 2014). A detailed elaboration of the complex process of tropoeslatin production and assembly into elastic fibers is outside the scope of this study. (We refer interested readers to other reviews (Vrhovski and Weiss, 1998; Mithieux and Weiss, 2005; Sherratt, 2009; Yeo et al., 2011; Reichheld et al., 2014; Wise et al., 2014).) In brief, following secretion, hydrophobic interactions cause tropoelastin molecules to form coacervates, which are subsequently deposited on pre-existing microfibrillar protein networks, which serve as the structural framework for the elastic fibers (Yeo et al., 2011; Wise et al., 2014). Lysyl oxidase (LOX) enzymes recruited to the coacervates, in part by microfibrillars such as fibulin-5 (Liu et al., 2004; Hirai et al., 2007), then oxidatively deaminate specific tropoelastin lysine residues to form allysines, which trigger spontaneous, but orientation-driven, formation of intra- and intermolecular cross-links (Siegel et al., 1970; Kagan and Sullivan, 1982; Broekelmann et al., 2005; Wachi et al., 2005) that are responsible for the $3 \mathrm{D}$ elastin fiber networks within the ECM. Cross-linked elastin is structurally restricted, and the resulting elastic fibers are insoluble, resistant to proteolytic degradation, and stable under mechanical stretching (Romero et al., 1986; Mecham, 1991; Bedell-Hogan et al., 1993; Vrhovski and Weiss, 1998; Sherratt, 2009).
Structurally, tropoelastin consists of an alternating arrangement of hydrophobic and hydrophilic (cross-linking) domains (Figure 2B). Hydrophobic domains are rich in nonpolar amino acids such as proline $(p)$, glycine $(G)$, valine $(V)$, and alanine $(A)$, usually arranged in combinations of $\mathrm{GV}$, GVA, and PGV motifs, and tend to be rich in GVGVP, GGVP, GVGVAP, and VPGFGVGAG repeats (Urry et al., 1990; Rodríguez-Cabello et al., 1999; Jensen et al., 2000; Acosta et al., 2020). These domains are highly disordered and flexible in solution, and this high entropy and hydrophobic character are responsible for the extensibility and restoring force of polymeric elastin and coacervation of tropoelastin (Vrhovski et al., 1997; Reichheld et al., 2014). These properties are affected by the type of amino acid sequence, domain type, and molecular weight, as well as other factors such as ECM pH, salts, and temperature. Indeed, optimal coacervation has been reported to occur at $150 \mathrm{mM}$ $\mathrm{NaCl}, 37^{\circ} \mathrm{C}$, and $\mathrm{pH}$ 7-8 (Vrhovski et al., 1997).

While coacervation is mainly driven by hydrophobic interactions, hydrophilic domains stabilize the structure of elastin through intra- and intermolecular covalent crosslinking of lysine $(K)$ side chains. These domains feature characteristic two or three lysines $(K)$ flanked by alanines $(A)$ (KA-type domains) or prolines $(p)$ and glycines $(G)$ (KP-type domains). Lysines are cross-linked by the enzyme lysyl oxidase, with subsequent condensation linking several side chains (Reichheld et al., 2014). KA-type cross-linking domains have been suggested to form an $\alpha$-helical secondary structure that is believed to facilitate formation of cross-links by bringing lysine residues together on the same face of the helix (Reichheld et al., 
2014). Just as is the case for hydrophobic domain, the amino acid sequence in the hydrophilic domains also affects polymer behavior. For instance, the presence of unstructured hydrophilic domain 26A, which is unique to human tropoelastin, is associated with protein hydration and the hindrance of aggregation. In addition, tyrosine-to-alanine mutations in the cross-linking domains of ELPs raised the coacervation temperature (Miao et al., 2003; Yeo et al., 2011).

\section{ELASTIN-LIKE POLYPEPTIDES AND RECOMBINAMERS}

Given that tropoelastin exhibits many of the intrinsic properties of the natural elastin, synthetic and soluble elastin-like polypeptides (ELPs), including the recombinant derivatives thereof, elastin-like recombinamer (ELR), and recombinant human tropoelastin (rh-TE) present a versatile alternative for the manufacture of ELP-based biomaterials for various biomedical applications. These synthetic derivatives of elastin recapitulate the properties of natural elastin such as biocompatibility, nonimmunogenicity, and biodegradability with biocompatible degradation byproducts, while overcoming the limitation of insolubility associated with natural elastin in biomaterials production (Nair and Laurencin, 2007; Sengupta and Heilshorn, 2010; Annabi et al., 2013a). Generally, these ELPs/ ELRs are composed of a (VPGXG) $)_{n}$ pentapeptide repeat unit derived from the hydrophobic domain of tropoelastin, where $\mathrm{X}$ can be any amino acid (guest amino acid) other than proline (Urry and Pattanaik, 1997; Girotti et al., 2004b; Meyer and Chilkoti, 2004; Rodríguez-Cabello et al., 2012; Kowalczyk et al., 2014) and the subscript $\mathrm{n}$ indicating the number of repeats, typically 20-330 (Meyer and Chilkoti, 2004; Tjin et al., 2014). Just as is the case with tropoelastin, ELPs/ELRs have a unique ability to undergo a sharp and reversible phase transition at a specific temperature known as the inverse transition temperature $\left(T_{t}\right)$ or lower critical solution temperature (LCST) (Urry et al., 1990; Urry and Pattanaik, 1997). This phase transition behavior is characterized by the formation of an insoluble coacervate phase above the $T_{t}$ of the polymer (Yeo et al., 2011; Wise et al., 2014; Roberts et al., 2015). Depending on the intended polymer application, ELP $T_{t}$ can be tuned to respond to different types of stimuli such as temperature, type and concentration of salts, cosolutes (i.e., proteins), $\mathrm{pH}$, and light (Roberts et al., 2015). This reversible phase behavior has been exploited in stimuli-assisted control of the polymer self-assembly into structures such as nanoparticles (Gonzalez-Valdivieso et al., 2019), films (Abbasi et al., 2020), hydrogels and porous scaffold (Nagapudi et al., 2005), and fibers (Putzu et al., 2018; SalinasFernández et al., 2020), with some finding use in drug delivery (Arias et al., 2018; Gonzalez-Valdivieso et al., 2019), tissue engineering (Roberts et al., 2015; Fernández-Colino et al., 2019b; Acosta et al., 2020; Gonzalez de Torre et al., 2020), and even clinical applications (Wang et al., 2015; Annabi et al., 2017b; Mithieux and Weiss, 2017; Shirzaei Sani et al., 2018; Wen et al., 2020). In the production of biomaterials such as hydrogels or material coatings, these parameters can be controlled at a molecular level in a modular manner to modulate, not only the biochemical properties but the physicochemical properties too, which include biomaterial pore size and porosity.

\section{Synthesis of ELRs}

While ELPs can be chemically synthesized (Urry et al., 1990; Urry and Pattanaik, 1997), drawbacks such as low yield and high impurity concentration, mainly due to the complexity and large molecular weight of ELPs, (Urry et al., 1990) have led to the development of biosynthesis-based methods (Girotti et al., 2011). These methods exploit the natural molecular pathways to produce recombinant polypeptides and allow for greater modular control of the amino acid sequence at a molecular level (Girotti et al., 2011; Rodríguez-Cabello et al., 2012). (For elaborate descriptions of the different molecular biology techniques used to produce ELRs, interested readers are directed at these references (Girotti et al., 2004b; RodríguezCabello et al., 2009; Girotti et al., 2011; Rodríguez-Cabello et al., 2012; Rodríguez-Cabello et al., 2017).)

In brief, the designed molecular sequence for a specific protein is first produced by polymerase chain reaction (PCR) or the directional ligation of the monomeric genes using approaches such as the recursive directional ligation by the plasmid reconstruction (PRe-RDL) method or the overlap extension rolling circle amplification (OERCA) method (RodríguezCabello et al., 2017; Acosta et al., 2020). The obtained molecular sequence or gene of interest is then transfected into a homogeneous host (e.g., eukaryotic cell, bacteria, yeast, fungi, and plants) where it is expressed and expanded for high yields (Acosta et al., 2020). Given that ELRs have an inherent LCST phase behavior, the synthesized polypeptides are purified from host materials through inverse transition cycling (ITC), which involves heating above the LCST to trigger coacervation, then centrifuging to collect the coacervate, followed by cooling below the LCST to solubilize the product and repeating the process until desired polymer purity, typically $>95 \%$, is attained (Urry and Pattanaik, 1997; Kowalczyk et al., 2014; Rodríguez-Cabello et al., 2017). Coacervation may also be triggered by increasing the ionic strength of the cell lysate to facilitate ELR aggregation, which can then be centrifuged out (Urry and Pattanaik, 1997; Girotti et al., 2004b; Rodríguez-Cabello et al., 2012; Kowalczyk et al., 2014).

\section{FORMATION OF ELR HYDROGELS}

The modular design and synthesis of ELRs and the ability to finetune polymer physicochemical properties by adjusting amino acid sequence have been widely used to produce ELR-based biomaterials with bespoke physical and biochemical properties for tissue engineering applications. ELRs in solution are generally stabilized into hydrogels by exploiting either the polymeric physical interactions to form hydrogels (physical crosslinking), or the formation of covalent cross-linking between polymer functional groups or separate cross-linking agents (chemical cross-linking) or a combination of both.

Generally, physical cross-links result from weak and usually reversible interactions such as hydrophobic polymer, protein and 
electrostatic interactions, hydrogen bonds, ionic interactions, crystallization, and stereocomplex formation (Memic et al., 2019). These interactions can be controlled by varying the amino acid sequences of the alternating blocks with opposed hydrophilicity, which allows fine-tuning of $T_{t}$ and the nature of polymer aggregation (Acosta et al., 2020), subsequently impacting scaffold porosity. For example, ELR sequences designed to form stable noncovalent interactions between polymer chains or to form stable $3 \mathrm{D}$ hydrophilic polymer networks capable of absorbing and retaining a significant amount of water at subzero temperatures are suitable for the production of porous scaffold by cryogelation or freeze-drying method (Zhang et al., 2017; Memic et al., 2019), where crosslinking is required to occur after (Zhang et al., 2017) or before (Offeddu et al., 2017) ice crystal formation and growth, respectively. The mechanical properties of these physical interactions can be further strengthened by incorporating structural sequences such as resilin or silk-derived motifs (Fernández-Colino et al., 2014; Huang et al., 2016; Cipriani et al., 2018; Acosta et al., 2020; Ibáñez-Fonseca et al., 2020a), and order-promoting sequences such as coiled-coil and leucine zippers (Fernández-Colino et al., 2015; Salinas-Fernández et al., 2020), which interact synergistically with the ELR domains (Fernández-Colino et al., 2015; Acosta et al., 2020). A detailed discussion of recombinant silk polymers is outside the scope of this review, and only silk derived motifs that are normally incorporated in the ELP/ELR design are mentioned in this work. The zipper sequences, found in the dimerization domain of the hepatic leukemia factor (HLF), improve the mechanical stability of zipper-ELR biomaterials, including pores, as they assemble into aggregate-promoting coiled-coil conformations. Additionally, the gelation time $(<30 \mathrm{~s})$ of silk- and zipper-ELR designs at $15 \mathrm{wt} \%$ concentration was found to be ideal for the formulation of injectable hydrogels under physiological conditions. Indeed, several of these modifications have been used to produce a stable ELR-based hydrogel bioink that benefitted from the formation of stable and insoluble silk $\beta$-sheet secondary structures, which endow mechanical and thermal resistance, $\alpha$-helical structural assembly of leucine zipper sequence, and the inherent thermal coacervation of ELRs (Elsharkawy et al., 2018). Although physical crosslinking methods offer a simple and rapid process for hydrogel fabrication that is free of chemical reactions, drawbacks such as poor and undesirable gel properties (e.g., fast degradation, brittleness, inadequate gel integrity, and rigidity) limit their application (Memic et al., 2019). Moreover, the reversible nature of physical cross-linking and the weak hydrophobic interactions sustaining the ELR-based hydrogel structure may confer undesired temperature-sensitiveness and insufficient mechanical properties for some tissue engineering applications, particularly where stability and controlled or no degradation are essential.

These drawbacks can be overcome by covalent (chemical) cross-linking, which produces hydrogels and scaffolds with more stable, better defined, and predictable properties (Memic et al., 2019). Commonly used covalent cross-linking approaches include free radical polymerization, which involves the formation of free radicals that lead to monomers or prepolymer cross-linking reactions (i.e., through redox group decomposition or photoinitiator), and Michael-type addition reaction, which is a nucleophilic addition of a carbanion or another nucleophile to an $\alpha, \beta$-unsaturated carbonyl compound that has an electron-withdrawing group (Nair et al., 2014; Hao et al., 2017). Michael-type addition is popular in the production of porous cryogels for drug delivery or tissue engineering applications due to associated superelasticity, high resilience, $\mathrm{pH}$-dependent swelling and degradation, and an extremely high recovery rate after storage at various temperatures (Memic et al., 2019). Varying the type, position, concentration, and spacing of the guest amino acids and or functionalized amino acids can be used to control the resulting covalent cross-linking, which in turn affects the scaffold stability and porosity. Although different functional groups can be used for chemical cross-linking, the use of amino groups in the lysine guest residues is most common. Indeed, chemical agents commonly used to stabilize ELRbased scaffolds include glutaraldehyde (Martino and Tamburro, 2001; Annabi et al., 2009a; Sallach et al., 2009a; Annabi et al., 2010), genipin (Vasconcelos et al., 2012; Reichheld et al., 2014; Putzu et al., 2016), carbodiimides (Lim et al., 2007; Zhang et al., 2015), diisocyanate (Sallach et al., 2009a), phosphines (Nettles et al., 2008; Wang et al., 2014; Haugh et al., 2018), and hydroxysuccinimide/diazirine derivatives (Raphel et al., 2012; Atefyekta et al., 2019), bis(sulfosuccinimidyl) suberate, and disuccinimidyl suberate (McMillan and Conticello, 2000). However, the cytotoxicity associated with these homofunctional cross-linkers and their reactionary byproducts limits their use, especially in applications requiring viable cell encapsulation and postimplantation in vivo curing (Raphel et al., 2012; Belsom and Rappsilber, 2021). Moreover, some of them have rapid cross-linking reactions that, in some cases, start as soon as the cross-linker is added with fast reaction kinetics that last as long as the mixing process, resulting in heterogeneous scaffold cross-linking and pore size (Raphel et al., 2012; Belsom and Rappsilber, 2021).

To address these drawbacks, other studies have explored the application of enzymes such as transglutaminase or lysyl oxidase for cross-linking (McHale et al., 2005), including cell encapsulation under mild conditions (McHale et al., 2005; Kubo et al., 2007; Annabi et al., 2009a). Recently, covalent disulphide bonds in a cysteine-containing SELR and noncovalent silk $\beta$-sheet $\mathrm{H}$-bonds have been used to produce biocompatible hydrogels by addition of hydrogen peroxide (Chen et al., 2017). Similarly, by encoding tyrosine cross-linking domains within an SELR sequence, an elastic and stable biocompatible hydrogel could be built by exploiting the silk-silk interactions coupled with the dityrosine covalent bonds in the presence of hydrogen peroxide and horseradish peroxidase (HRP) (Huang et al., 2016). Recently, González de Torre et al. reported a rapid, tuneable, and cell-friendly crosslinking method that exploits the 1,3-dipolar cycloaddition "click chemistry" reaction between azides and alkynes, which react orthogonally to form an irreversible covalent bond (González de Torre et al., 2014). Although this catalyst-free strain-promoted 


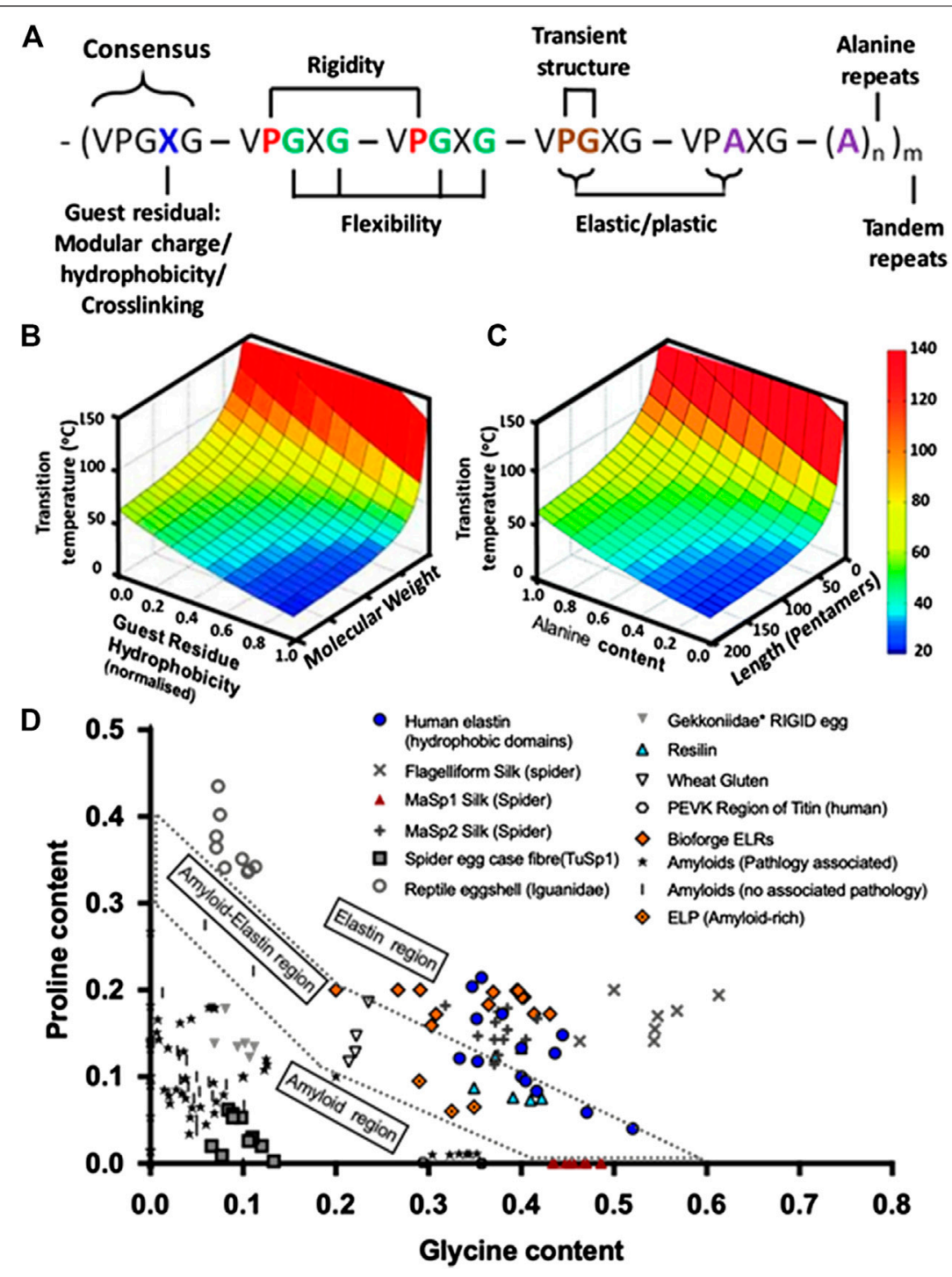

FIGURE 3 | (A) Schematic representation of some of the domains and position that can be varied at the sequence level to control of polypeptide disorder state and subsequently scaffold properties (i.e., guest amino acid type, P/G and PA content, polyalanine content, and tandem repeats) (adapted from Roberts et al. (2015). (B) A 3D plot of predicted $T_{t}$ landscape in relation to guest residue hydrophobicity and polypeptide molecular weight (adapted with permission from Roberts et al. (2015), copyright 2015, John Wiley and Sons) as well as (C) in relation to alanine content and the number pentapeptides in the polypepyide (reproduced with permission from McDaniel et al. (2013), copyright 2013, American Chemical Society). Depending on the amino acid sequence, the aforementioned temperature of transition can be either completely reversible or irreversible. (D) Proline and glycine composition of elastomeric and amyloidogenic sequences for a wide variety of polypeptides (adapted from Rauscher et al. (2006)). The amyloid-elastin coexistence region (doted perimeter) contains $p$ and $\mathrm{G}$ compositions consistent with both amyloidogenic and elastomeric properties. On the top right of the doted zone appear elastomeric proteins and bottom left are amyloidogenic sequences, along with spider egg and gecko egg protein. Elastomeric-amyloid tunability can be seen in the spread of ELRs (Bioforge group) from very elastomeric to the coexistence border, with some amyloid-rich ELPs by others (Miao et al., 2003; Rauscher et al., 2006) falling, by design, within the coexistence border. (Refer to the Supplemental Data for sequences and corresponding references.)

alkyne-azide cycloaddition (SPAAC) method is rapid, azide-alkyne specificity affords control and fine-tuning of the cross-linking reaction, including working under ambient condition. Indeed, the biocompatibility of SPAAC-cross-linked ELRs has been demonstrated with different cell types (Testera et al., 2015) and exploited for different tissue engineering applications (Misbah et al., 2017; Fernández-Colino et al., 2019a; Ibáñez-Fonseca et al., 2020b). Given the biocompatibility of this cross-linking, $T_{t}$ may be adjusted to physiological conditions, to allow cross-linking with or without cargo cells and or drugs (Annabi et al., 2017b; Roberts et al., 2018; Cipriani et al., 2019). Other researchers have incorporated methacrylated residues on ELRs to produce photocurable hydrogels (Shirzaei Sani et al., 2018) using only 
TABLE 2 | Common approaches used to control polymer physicochemical properties for porous scaffold development.

\begin{tabular}{|c|c|c|c|c|c|}
\hline $\begin{array}{l}\text { Recombinant } \\
\text { polymer design }\end{array}$ & Modification & Physical property & Pore size & Application & References \\
\hline $\begin{array}{l}\text { Hydrophilic/ } \\
\text { hydrophobic } \\
\text { character }\end{array}$ & $\begin{array}{l}\text { (VPGXG) polar/nonpolar fourth guest amino } \\
\text { acid }\end{array}$ & $\begin{array}{l}\text { Increase/decrease } \\
\text { transition } \\
\text { temperature } \\
\text { aqueous solution }\end{array}$ & 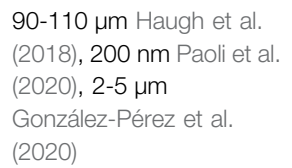 & $\begin{array}{l}\text { hMSCs (Haugh et al. (2018), } \\
\text { membrane Paoli et al. } \\
\text { (2020), and membrane } \\
\text { González-Pérez et al. } \\
\text { (2020) }\end{array}$ & $\begin{array}{l}\text { Haugh et al. (2018), } \\
\text { González-Pérez et al. } \\
\text { (2020), and Paoli et al. } \\
\text { (2020) }\end{array}$ \\
\hline $\begin{array}{l}\text { Interchanging } \\
\text { proline with } \\
\text { glycine }\end{array}$ & (VPGXG) & $\begin{array}{l}\text { Control amount of } \\
\text { secondary type II } \\
\beta \text {-turns in the } \\
\text { polymer, degree of } \\
\text { aggregation, and } \\
\text { transition } \\
\text { temperature }\end{array}$ & $\begin{array}{l}\text { Pore size and porosity not } \\
\text { given (Fu et al., 2009) }\end{array}$ & & Fu et al. (2009) \\
\hline $\begin{array}{l}\text { Amphiphilic } \\
\text { block } \\
\text { arrangement }\end{array}$ & $\begin{array}{l}\left(V P G X_{1} G\right)_{n}\left(V P G X_{2} G\right)_{m}, \text { Where } X_{1} \text { and } X_{2} \\
\text { have opposite polarity }\end{array}$ & $\begin{array}{l}\text { Adjust transition } \\
\text { temperature and } \\
\text { promotes polymer } \\
\text { aggregation }\end{array}$ & $\begin{array}{l}50 \mathrm{~nm} \text { (Misbah et al., } \\
\text { 2015) }\end{array}$ & & Misbah et al. (2015) \\
\hline $\begin{array}{l}\text { Plastic-like } \\
\text { domains }\end{array}$ & {$\left[(I P A V G)_{4}(V P A V G)\right]_{n}$ sequence } & $\begin{array}{l}\text { Introducing } \\
\text { secondary } \alpha \text {-helix } \\
\text { and } \beta \text {-sheet } \\
\text { structures and } \\
\text { endows plastic } \\
\text { properties }\end{array}$ & $\begin{array}{l}2-20 \mu \mathrm{m} \text { (Sallach et al., } \\
\text { 2009b), } 500 \mathrm{~nm} \text { (da Costa } \\
\text { et al., 2017) }\end{array}$ & $\begin{array}{l}\text { Wound healing (da Costa } \\
\text { et al., 2017) }\end{array}$ & $\begin{array}{l}\text { Sallach et al. (2009b), } \\
\text { and da Costa et al. } \\
\text { (2017) }\end{array}$ \\
\hline $\begin{array}{l}\text { Polyalanine } \\
\text { motifs }\end{array}$ & $\left(A_{n}\right)_{m}$ sequence & $\begin{array}{l}\text { Introducing } \\
\text { secondary a-helix } \\
\text { and endows } \\
\text { viscoelastic } \\
\text { properties }\end{array}$ & $\begin{array}{l}\text { 3-50 } \mu \mathrm{m} \text { (Roberts et al., } \\
\text { 2018) }\end{array}$ & $\begin{array}{l}\text { Subcutaneously applied in } \\
\text { female C57BL/6 mice } \\
\text { (Roberts et al., 2018) }\end{array}$ & Roberts et al. (2018) \\
\hline $\begin{array}{l}\text { Leucine zipper } \\
\text { motifs }\end{array}$ & $\begin{array}{l}\text { (KENQIAIRASFLEKENSALRQEVADLRKE (L/ } \\
\text { C)GKCKNILAKYEA) sequence }\end{array}$ & $\begin{array}{l}\text { Introducing } \\
\text { secondary } a \text {-helix }\end{array}$ & $\begin{array}{l}\text { 20 um (Fernández-Colino } \\
\text { et al., 2015), } 5 \mu \mathrm{m} \\
\text { (Salinas-Fernández et al., } \\
\text { 2020) }\end{array}$ & $\begin{array}{l}\text { Human foreskin fibroblast } \\
\text { HFF-1 (Fernández-Colino } \\
\text { et al., 2015), HFF-1, and } \\
\text { HUVEC, hMSCs } \\
\text { (Salinas-Fernández et al., } \\
\text { 2020) }\end{array}$ & $\begin{array}{l}\text { Fernández-Colino et al. } \\
\text { (2015), and } \\
\text { Salinas-Fernández et al. } \\
\text { (2020) }\end{array}$ \\
\hline Silk-like motifs & $\begin{array}{l}\text { (GAGAGS })_{n} \text { sequence from Bombyx mori } \\
\text { worm silk fibroin }\end{array}$ & $\begin{array}{l}\text { Introducing } \\
\text { secondary } \beta \text {-sheet } \\
\text { structures }\end{array}$ &  & $\begin{array}{l}\text { hMSCs (Ibáñez-Fonseca } \\
\text { et al., 2020a), pig } \\
\text { chondrocytes, HFF-1, and } \\
\text { ex vivo osteochondral } \\
\text { explants (pig knee joint) } \\
\text { (Cipriani et al., 2018), } \\
\text { hMSCs (Huang et al., 2016) }\end{array}$ & $\begin{array}{l}\text { Huang et al. (2016), } \\
\text { Cipriani et al. (2018), } \\
\text { and lbáñez-Fonseca } \\
\text { et al., (2020a) }\end{array}$ \\
\hline $\begin{array}{l}\text { Tropoelastin-like } \\
\text { motif }\end{array}$ & $\begin{array}{l}\text { Replication of the } 27-724 \text { amino acid } \\
\text { residues of the human tropoelastin }\end{array}$ & $\begin{array}{l}\text { Introducing } \\
\text { secondary a-helix, } B \text { - } \\
\text { sheet, and type II B- } \\
\text { turn }\end{array}$ & 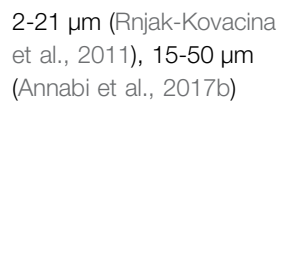 & $\begin{array}{l}\text { (DHF) and in vivo } \\
\text { subcutaneous in mice } \\
\text { (Rnjak-Kovacina et al., } \\
2011 \text { ), endothelial } \\
\text { progenitor cells (EPCs), in } \\
\text { vivo and ex vivo on rat } \\
\text { arteries/lungs, and porcine } \\
\text { lungs (Annabi et al., 2017b) }\end{array}$ & $\begin{array}{l}\text { Rnjak-Kovacina et al. } \\
\text { (2011) and Annabi et al. } \\
\text { (2017b) }\end{array}$ \\
\hline
\end{tabular}

canonical amino acids. Thio groups from cysteine residues in the ELP sequence have also been used to form disulfide bonds under UV light exposure, resulting in highly stable and elastic hydrogels (Zhang et al., 2015). While it is generally accepted that scaffold pore size and porosity are inversely proportional to the concentration of polymer and the degree of cross-linking, with ELR polymers, the order of cross-linkable domain arrangement and amount thereof can also affect not only pore size and porosity but scaffold homogeneity and scaffold stability too (Lim et al., 2008).
In these approaches, weaker physical cross-linking may be used to produce softer matrix to facilitate early cell infiltration, while stronger covalent cross-linking can be used to impart scaffold stability and integrity while it supports the newly developing tissue, including complex structures such as blood vessels in vivo. While the type of cross-linking used can affect scaffold integrity and stability, different adjustments to the amino acid sequence and domain chemistry have been developed to optimize the biological and physicochemical properties of the resulting scaffolds, including pore size and porosity. 


\section{Strategies for Controlling Physicochemical Properties of Porous ELR Hydrogels}

The intrinsic high conformational flexibility at low temperature and disordered molten globule aggregation at high temperature associated with the consensus ELR repeat unit VPGXG present a flexible parameter that can be controlled to fine-tune several scaffold features. Some of these include the type of guest residue $(X)$ and the number of replicates, proline/glycine (PG) content, the number of tandem $(n)$ repeats, and the domain amino acid sequence modifications and insertions (Figure 3) (RodríguezCabello et al., 2009; Girotti et al., 2011; Yeo et al., 2011; Roberts et al., 2015; Ibáñez-Fonseca et al., 2020a). Select examples of different ELR sequence and structure adjustments that can be used to control physicochemical properties of porous ELR-based scaffolds are listed in Table 2.

Alterations in the identity of the fourth amino acid $(X)$ of the hydrophobic and elastic conferring domains (VPGXG) have been widely used to modulate the position of polypeptide $T_{t}$ in aqueous solutions (Fu et al., 2009; Girotti et al., 2011; Roberts et al., 2015; Huang et al., 2016; Ibáñez-Fonseca et al., 2019), which is consummate to the effect of the polarity and concentration of the guest amino acid side chain on the polymer-solvent interaction (Nagapudi et al., 2005). It is well established that placing polar amino acids (e.g., glutamic acid, lysine, or cysteine) or nonpolar amino acids (e.g., isoleucine, valine, or alanine) on the $X$ position can increase or decrease, respectively, the ELR coacervation temperature in aqueous solution (Figures 3A,B) (Urry et al., 1992; Rodríguez-Cabello et al., 2009; Girotti et al., 2011; Roberts et al., 2015; Ibáñez-Fonseca et al., 2020a), which can subsequently impact scaffold porosity (Heydarkhan-Hagvall et al., 2008; Lim et al., 2008; Fu et al., 2009; Haugh et al., 2018). Additionally, functional groups on the guest amino acids can be used as cross-linking anchoring points to produce stable $3 \mathrm{D}$ networks while preserving the elastic and bioactive properties of ELRs. In this regard, lysine guest residues are commonly used for covalent cross-linking of 3D porous ELR scaffolds, and the degree of physical or covalent cross-linking can be modulated to fine-tune scaffold stability and water-holding capacity (IbáñezFonseca et al., 2019; Acosta et al., 2020). Where cell encapsulation and or in vivo curing is needed, which requires noncytotoxic cross-linking, $T_{t}$ may be adjusted to facilitate physical crosslinking and gelation under physiological conditions (Annabi et al., 2017b; Roberts et al., 2018; Cipriani et al., 2019).

Given that cross-linking is impacted by the type, amount, and distribution of cross-linking amino acids and how these residues are presented to each other or to the cross-linking agent, approaches that modify ELR secondary structures (i.e., beta $(\beta)$ turns and helicity) have been widely explored. For instance, since PG-dipeptide units in the consensus pentapeptide (VPGXG) are responsible for the corners (bends) in type II $\beta$-turns in ELRs, which are critical for the polymer aggregation, replacing $p$ with $G$ is reported to reduce stability of the $\beta$-turns (Debelle and Tamburro, 1999; Jensen et al., 2000; Rauscher et al., 2006; Fu et al., 2009). Moreover, substituting the consensus glycine $(G)$, the third residue of the hydrophobic repeat sequence, with alanine $(A)$ can be used to shift between ELR elastic responses (elastomeric) and plastic deformation (amyloid) (Figures 3A,C,D) (Rauscher et al., 2006; Fu et al., 2009; Yeo et al., 2011). This is because substituting PG with PA in the repeat pentapeptide changes type II $\beta$-turn to a type I and can be varied to fine-tune domain orientation, polymer $T_{t}$, and elastic-plastic properties of the ELR (Rauscher et al., 2006; Fu et al., 2009; Yeo et al., 2011). Indeed, while poly(VPGG) and poly(VPGVG) are known to coacervate reversibly, poly(APGVGV) precipitate irreversibly (Jensen et al., 2000), and ELPs lacking the PG dipeptide (i.e., poly(VGGLG)) are unable to coacervate (Vrhovski et al., 1997; Jensen et al., 2000; Rauscher et al., 2006; Fu et al., 2009).

Similarly, hydrophobic-hydrophilic domain arrangements have been used to produce amphiphilic polypeptide designs that can physically self-assemble by the formation of secondary type II $\beta$-turns into porous hydrogels (Misbah et al., 2015). This ability to fine-tune the elastic-plastic properties of ELRs can be used to control the reduction in size of ELR scaffold pores from that of progene due in part to elastic recoil and temperature-driven swelling widely associated with elastin-based materials. Indeed, depending on the amino acid sequence and overall molecular weight, ELRs display varying $T_{t}$ and a broad range of mechanical and viscoelastic responses ranging from plastic to elastic (Nagapudi et al., 2005; Martín et al., 2009b; Martín et al., 2010).

Indeed, while these amphiphilic ELR are commonly used for the development of micelles, several studies have demonstrated their efficacy in the production of porous scaffold (Misbah et al., 2015). Recently, by increasing the concentration of an amphiphilic diblock [(VPGVG) $)_{2}$-VPGEG-(VPGVG) $\left.)_{2}\right]_{10}(\text { VGIPG) })_{60}$ from 1 to $100 \mathrm{mg} / \mathrm{ml}$, the formed structures evolved from nanoparticles to lyotropic hydrogels composed of fibrillar structures exhibiting hexagonal packing (Misbah et al., 2015). In this arrangement, the glutamic acid-rich hydrophilic block [(VPGVG) ${ }_{2}$-VPGEG$\left.(\mathrm{VPGVG})_{2}\right]_{10}$ has a high $T_{t}\left(100^{\circ} \mathrm{C}\right)$ at neutral $\mathrm{pH}$ and stays hydrated and relatively extended at any temperature, while the hydrophobic block (VGIPG) ${ }_{60}$ retains self-assembly capabilities at a set $T_{t}$ (Girotti et al., 2004a; Misbah et al., 2015). Similarly, an amphiphilic triblock polypeptides comprising hydrophobic plastic monomer endblocks $\left[(\mathrm{IPAVG})_{4}(\mathrm{VPAVG})\right]_{\mathrm{n}}$ with $T_{t}\left(\mathrm{~T} \sim 20^{\circ} \mathrm{C}\right)$, separated by a central hydrophilic elastomeric block containing the monomer sequence $\left[(\mathrm{VPGVG})_{4}(\mathrm{VPGEG})\right]_{\mathrm{m}}$ with $T_{t}\left(>37^{\circ} \mathrm{C}\right)$, was reported to be suitable for producing electrospun porous scaffold (Nagapudi et al., 2005). However, given the difference in the $T_{t}$ of the blocks, while the hydrophobic endblock phase separates from aqueous solution under physiologically relevant conditions ( $\left.\mathrm{pH} 7.4,37^{\circ} \mathrm{C}\right)$, the hydrophilic block would maintain conformational flexibility at this temperature. Elsewhere, the potential of the physically cross-linkable (IPAVG) ${ }_{4}(\mathrm{VPAVG})$ domains to trigger the transformation of helical assemblies into secondary structures that confer plastic-like properties has been used to produce rigid-structured porous scaffolds (Lao et al., 2007; Sallach et al., 2009b). In other studies, interspacing the silk-like domains (GAGAGS) from the Bombyx mori fibroin in the ELR or ELP sequence has been shown to impart the formation of secondary $\beta$-sheet structures (Fernández-Colino et al., 2014). However, unlike the rapid phase transition of elastomeric 
domains, the self-assembling kinetics of silk-like domains occur at a slower rate and produces stable physically cross-linked hydrogels with intrinsic porosity and biocompatibility (Huang et al., 2016; Kawabata et al., 2017; Cipriani et al., 2018; Ibáñez-Fonseca et al., 2020a).

Elsewhere, others have demonstrated the indirect control of hydrophobic domain properties by modifying the hydrophilic domain. In this regard, the inclusion of ordered nonelastic domains such as polyalanine motifs $\left(\left(\mathrm{A}_{\mathrm{n}}\right)_{\mathrm{m}}\right)$, which are present in human tropoelastin and known to increase helical content, in the ELR backbone can promote the formation of stable physically cross-linked $\alpha$-helical bundles in aqueous environments (Miller et al., 2002; Kumashiro et al., 2006; Bernacki and Murphy, 2011). In addition, replacing the hydrophilic GVGTP hinge with AAAAA in the cross-linking domain $21 / 23$ in the elastin peptide representing domains 20-21/23-24-21/23-24 was shown to significantly lower $T_{t}$ from 29 to $12.5^{\circ} \mathrm{C}$ (Kumashiro et al., 2006). It was suggested that alanine substitution of the hinge increases polymer helicity, leading to a loss of flexibility that facilitates aggregation between proximal hydrophobic domains. This demonstrates how adjustments to hydrophilic sequences can indirectly modulate the polymer properties (i.e., $T_{t}$ and dissolution) (Yeo et al., 2011) that ultimately impact scaffold characteristics. Indeed, modulation of polyaniline-derived helicity and polymer concentration was recently used to control void volume (porosity) and pore size between $90 \%$ ( $\sim 30-50 \mu \mathrm{m}$ pores) and $60 \%(\sim 3-5 \mu \mathrm{m}$ pores) (Roberts et al., 2018). The increase in helical content was shown to lead to loss of flexibility, lower $T_{t}$, and facilitate aggregation between proximal hydrophobic domains and polymer-phase separation that counters the Newtonian fluid behavior of ELRs, which produce viscoelastic porous networks, with pore size and porosity being affected by polymer concentration (Kumashiro et al., 2006; Yeo et al., 2011; Roberts et al., 2018). In addition to helical percentage, molecular weight adjustments could also be used to modulate the $T_{t}$ and material stiffness of the ELR-based scaffolds. Indeed, the adjustable $T_{t}$ can be used to develop injectable ELR formulations that can form viscoelastic gels at body temperature (Roberts et al., 2018). In another approach, the inclusion of leucine zippers ( $Z$-domains) that form reversible dimeric coiled-coil $\alpha$-helical structures in the ELR sequence was used to enhance polymer stability and induced the creation of micelles at a particular $T_{t}$, which subsequently evolved into stable and highly porous hydrogels (Fernández-Colino et al., 2015). This property by the Leucine zippers can be exploited in the development of injectable formulations that gel under physiological conditions and the reversible physical interactions and mechanical properties that can decrease with time, if undesired, can be stabilized further by incorporating approaches such as cysteine-based stabilization through the formation of covalent disulfide bonds (Fernández-Colino et al., 2015; Salinas-Fernández et al., 2020).

In instances where the inclusion of sequences with desired biological properties compromises the physicochemical properties of the polymer and desired scaffold features such as porosity and pore size, a combination of different approaches may be used. For instance, while the amino acid residues 27-724 of the native tropoelastin sequence endow the porous scaffolds with elastic response, as well as promoting cell attachment, spreading, and proliferation, this sequence compromises hydrogel stability. As such, different approaches such as the addition of glutaraldehyde (Rnjak et al., 2009), the modification of ELRs with methacrylate groups (Annabi et al., 2013b; Annabi et al., 2017b), or the combination with biomaterials such heparin or dermatan sulfate in the presence of bis(sulfosuccinimidyl) suberate (BS3) (Tu et al., 2010) have been used to stabilize porous hydrogels for tissue engineering using ELRs containing this sequence.

Considering that the process of wound healing and tissue regeneration is dynamic, characterized by an ever changing cellular microenvironment, cell differentiation, migration, and the development and infiltration of complex structures (i.e., angiogenesis and re-enervation), scaffold adaptability that is reciprocal and complementary to the biological changes is vital. In addition to polymer elasticity and scaffold flexibility that allow scaffold pore adaptability to infiltrating cells and complex features such as new ECMs and blood vessels, others have exploited the modular design of ELRs to produce polymers with sequences that allow controlled and reciprocal biodegration. Recently, ERL-based hydrogels containing domains labile to tissue plasminogen activator (tPA) and urokinase plasminogen activator ( $\mathrm{PPA}$ ) enzymes demonstrated a highly tunable biodegradation rate, entailing adaptable porosity, which was dependent on the concentration of the enzymes and the duration of exposure (Straley and Heilshorn, 2009). Similarly, by incorporating two uPA labile epitopes with amino acid sequences GTAR and DRIR for their respective fast and slow proteolytic kinetics and enzyme sensitivities, into the sequence of two ELRs, the rate of cell infiltration could be regulated. In this work, a 3D ELR-based hydrogel composed of fast degrading DRIR-ELR on the center and slowly degrading GTAR-ELR on the outside had cells colonizing the inner layer first followed by the outer layer (Flora et al., 2019b). Similarly, degradable ELR-based hydrogels with different proteolytic cleavage kinetics and different network architectures have been developed. In this regard, by varying the functionality of the cross-linkers such in a multiarm poly(ethyleneglycol) (PEG) cross-linkers or in bioorthogonal SPAAC reaction-stabilized ELR networks, hydrogels with different biodegradation fragments that have different proteolytic cleavage kinetics were produced. In this work, the endowment of a rapid and total excision of the internal architecture of the hydrogel supported the formation of an endothelial network in situ (LeSavage et al., 2018). The tunability of this approach is especially important as it can be adapted to support regeneration of different tissue types.

\section{ELR-BASED POROUS BIOMATERIALS IN TISSUE ENGINEERING}

Given the heterogeneity of the ECM within and across the different tissues of the body and associated healing profile variation, the modular control of ELR physicochemical properties, achievable at a molecular level, presents an 

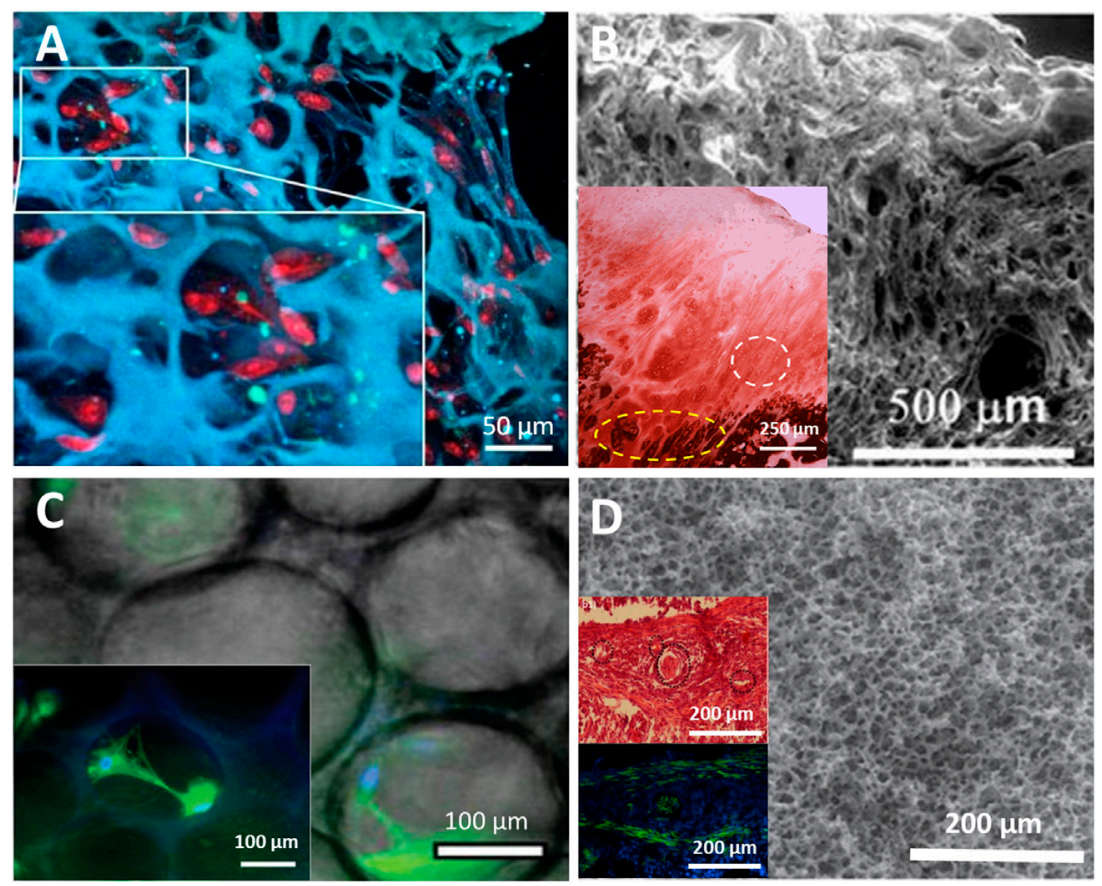

FIGURE 4 | Cell interactions with porous scaffolds: (A) ELR scaffold hydrogel produced by gas foaming with proliferation of SMCs (cross section reproduced with permission from Fernández-Colino et al. (2018). (B) Physically cross-linked ELR porous scaffold showing complete articular cartilage regeneration (white dotted line in inset) and areas of ossification (yellow dotted line in inset) in vivo (SEM and histological results reproduced with permission from Pescador et al. (2017), copyright Springer Nature, 2017). (C) ELR porous scaffold produced with physical interactions, showing good cell viability with hMSCs growing within pores (inset) (micrographs reproduced with permission from lbáñez-Fonseca et al. (2020a), copyright 2020, John Wiley and Sons); (D) Click chemistry cross-linked ELR porous scaffold containing enzyme-labile sequences, supported the development of robust blood vessels as it degraded in a reciprocal manner (SEM, histochemical (top) and immunohistochemical (bottom) images (insets) reproduced with permission from Flora et al. (2019b), copyright 2019, Institute of Physics).

attractive flexible technological platform for the development of bespoke materials for different tissue engineering applications. Depending on the intended application, different polymer modifications can be optimized to endow the resulting porous scaffolds with desired physicochemical properties and control different cellular activities such as infiltration, differentiation, and activation. This versatility has been explored for different applications in the regeneration of different tissues such as cardiovascular, dermal repair, and skeletal regeneration. Representative examples of cells interacting with ELR-based porous scaffold developed for different tissue engineering applications are shown in Figure 4, and a brief overview of this is provided hereinafter.

\section{Cell Encapsulation}

The well-established biocompatibility and nonimmunogenic qualities of ELPs and ELRs make formulations thereof ideal coating materials to shield cells from harsh environments, including immune rejection in allogeneic and xenogeneic grafting. Owing to the versatility of ELR technological platform, ELR polymers functionalized for various applications have been widely used to encapsulate many different cells types (LeSavage et al., 2018; Kratochvil et al., 2019); cocultures, including organoids development (DiMarco et al., 2015; Kratochvil et al., 2019); and in vivo using covalent and or physical cross-linking (Annabi et al., 2017b; Coletta et al., 2017; Cipriani et al., 2018; Roberts et al., 2018; Gonzalez de Torre et al., 2020). For instance, recently, an ELP-based 3D alternative to $2 \mathrm{D}$ cell culture systems, with proteolytic and cell adhesion domains successfully encapsulated cargo adult murine neural progenitor cells (NPCs) by covalent cross-linking with improved viability over 7 days, which was attributed to an adequate microenvironment for cells (LeSavage et al., 2018). In another study, thermic hydrophobic collapse of ELR was used to entrap cargo pancreatic cells in a smooth and porous scaffold that was flexible enough to allow cytoskeletal and cell cluster expansion in situ and was robust and biocompatible enough to protect cargo cells from host immune recognition and promote the development of viable insulin-secreting islets in murine models (Lee et al., 2019).

During cell resuspension in polypeptide mixture, the shrinkage of cells, several-fold their normal size, and their subsequent pooling to the bottom are associated with poor cell homogeneity and delayed proliferation. To address this drawback, Poocza et al incorporated specific cholesterol domains in ELR structure to promote polymer coordination with cell membranes, thereby improving cell affinity for the matrix (Poocza et al., 2019). Indeed, encapsulation of HUVEC and HASMC showed scaffold cytocompatibility, with the latter showing a higher affinity for the matrix. Moreover, cell 
attachment and distribution increase with an increase in the amount of cholesterol groups per ELR chain (Poocza et al., 2019). Other bioactive sequences and molecules that can be incorporated to improve cell attachment, viability, and distribution include the widely used RGD (Salinas-Fernández et al., 2020) and chemotactic domains such as elastokine (XGXXPG) and laminin (LGTIPG) sequences (Duca et al., 2004). Moreover, other physicochemical parameters can also be modulated by adjusting the amino acid sequence. For instance, leucine zipper and silk domains can be used to impart suitable mechanical properties to support and protect cells during scaffold formulation in 3D printing. In this regard, the leucine zipper domains endow a coiled-coil conformation, bringing the polypeptide chains together leading to silk $\beta$-sheet stabilized by H-bonds interactions (Kumashiro et al., 2006; Fernández-Colino et al., 2015; Salinas-Fernández et al., 2020).

\section{Cardiovascular Devices}

In addition to qualities such biocompatibility, bioactivity, and biodegradability generally sought after for tissue engineering materials, additional qualities such as elasticity, electroconductivity, and antithrombogenicity are important for cardiovascular applications. Given that elastin is one of the principal components of cardiovascular ECM and the fact that the physicochemical and bioactive properties of ELP/ELRs are tunable on demand as per intended application, ELP/ELR-based biomaterials present an attractive flexible option to meet most of these requirements. In this regard, inherently elastic and bioactive ELRs (poly(VPGXG)) present a versatile solution with known antithrombogenicity (i.e., poly(VPGIG), poly(VPGVG)) for building and or decorating cardiovascular devices (Woodhouse et al., 2004; Jordan et al., 2007; González de Torre et al., 2015; Mahara et al., 2017; Gonzalez de Torre et al., 2020). Indeed, several porous ELP/ELR-based scaffolds with bespoke stiffness varying from a few hundreds to tens of thousands of Pascals, depending on intended application, have been reported in the literature (González de Torre et al., 2015; Gonzalez de Torre et al., 2016; Cipriani et al., 2018; Gonzalez de Torre et al., 2020).

Recently, a porous scaffold of two complementary SPAACclickable ELR polypeptides produced by gas foaming for cardiovascular application promoted the infiltration, attachment, and proliferation of smooth muscle cells (SMCs) in situ (Fernández-Colino et al., 2018). While the scaffold compactness, flexibility, and rigidity can be adjusted by controlling the degree of cross-linking, the lack of reciprocity in the cell-scaffold interactions can potentially impede regenerating tissue. To address this, Madl et al showed that by incorporating a uPA enzyme-labile sequence in SPAAC-crosslinkable RGD-containing ELR matrices, biodegradation could be controlled by varying the degree of cross-linking (Madl et al., 2018). Indeed, a 5-day challenge of the resulting scaffold with uPA expressing murine brain microvascular cells showed increased cell infiltration characterized by widely spread endothelial cell networks with characteristic elongated cell shapes in hydrogels with less cross-linking units and significantly lower cell spreading in slowly degrading highly cross-linked hydrogels. However, although this demonstrates tunable biodegradation, the degree to which crosslinking-depended biodegradation can continue to reiteratively adapt to continuous cell infiltration and ECM remodeling is limited. Alternatively, others developed ELRs with biodegradation that is dependent on the degree of enzyme liability and not cross-linker. In this regard, bulk biomaterials designed to degrade quicker (faster enzymatic degradation) on the inside and slower on the outer layers showed quicker cell infiltration in the interior of the implant, which gradually reduced toward the outer layers, thereby allowing for uniform implant colonization by cells (Flora et al., 2019a). The subsequent development of blood vessels at the core of the implant, which would normally be limited to the surface, and the eventual complete degradation of the materials synergistically replaced by robust newly formed tissue showed how effective material-host tissue reciprocity is important for tissue regeneration, especially in hard-to-repair cardiovascular tissue (Flora et al., 2019a). In another study, it was reported that exposed elastin sequences can increase the levels of matrix metalloproteinases (MMP-2), which contribute to the digestion of connective tissue growth factor (CTGF) and, together with transforming growth factor (TGF- $\beta 1$ ), increase the amount of free vascular endothelial growth factor (VEGF), thereby improving angiogenesis activity (Reddel et al., 2013).

These properties can be improved upon and controlled by introducing other proangiogenic molecules as cargo molecules or as part of the polymer sequence. Indeed, sequences such as those for cell adhesion (i.e., RGD and REDV) (Hubbell et al., 1991), monocyte attractive motif (i.e., VGVAPG), a human adipose tissue-derived stromal vascular fraction (SVF) cell (Staubli et al., 2017), and proangiogenic VEGF1650mimicking QK peptide (KLTWQELYQLKYKGI) (Andrea et al., 2005) have been used to facilitate the formation of capillaries and blood vessels in vivo as well as trigger vascularization and host-cell colonization of scaffolds (Testa et al., 2008; Flora et al., 2019a).

Considering that angiogenesis is key to regeneration of other different tissues, this versatility has been explored for different applications in the regeneration of other tissues (Gonzalez de Torre et al., 2020). Recently, a layer-by-layer dip-coating with SPAAC-cross-linkable ELR hydrogel of cobalt chromium (CoCr) stents produced a continuous porous surface membrane robust enough for the implantation procedure (balloon dilatation) and high flow conditions, and supported the formation of a scaffold infiltrating human endothelial progenitor cell (EPC) layer (Fernández-Colino et al., 2019a). Crucially, no platelet adhesion was observed when the scaffold was exposed to human blood. To improve robustness of the porous membrane coat, ELR polypeptide can be covalently linked to the prosthesis for improved hemocompatibility (Castellanos et al., 2015) characterized by minimal fibrinogen and platelet adhesion and robustness enough to withstand shear stress of $2 \mathrm{~Pa}$ (González de Torre et al., 2015). Elsewhere, the high porosity of a small diameter tubular scaffolds containing RGD and REDV produced by electrospinning with genipin as a cross-linker showed increased adhesion, infiltration, and proliferation of HUVECs (Putzu et al., 2016; Putzu et al., 2018). 


\section{Dermal Applications}

Although elastin accounts for only 2-4\% dry weight of skin, it is responsible for skin elasticity, and its physicochemical properties have been reported to regulate cell behavior (Wen et al., 2020). However, although elastin has a long half-life ( $>70$ years) and contributes to scar-free healing in fetal wounds, the poor production of elastin in adulthood and its absence in adult wound healing make elastin and mimetic derivatives a logical addition to wound healing biomaterials (Wen et al., 2020). It is well established that an ideal wound healing material needs to promote wound closure, support and sustain remodeling, prevent wound infection, and be immunocompatible.

Given the importance of reducing the risk of infection and loss of fluids in wound management, several ELP/ELR-based materials have been developed for improved early wound closure. In this regard, Brennan et al developed a musselinspired biocompatible and adhesive ELR curable under wet conditions by enzymatically modifying in-structure tyrosine amino acids to 3,4-dihydroxyphenylalanine (DOPA) (Brennan et al., 2017). Associated drawbacks such as the limited control over the runaway curing reactions that limit the applicability of this adhesive can be solved by introducing stimuli-directed curing (i.e., UV and/or photoinitiator). Recently, a photocurable ELPbased porous hydrogel exploiting cysteine-based radical polymerization under UV for stemming bleeding demonstrated that increasing polymer concentration (from $10 \%$ to $15 \%$, and $20 \%(\mathrm{w} / \mathrm{v}))$ decreased the pore size (from $4.70 \pm 0.48 \mu \mathrm{m}$ to $1.58 \pm 0.24 \mu \mathrm{m}$ and $1.53 \pm 0.20 \mu \mathrm{m})$ and swelling ratio (from $207 \pm 32 \%$, to $156 \pm 10 \%$, and $138 \pm$ $19 \%$ ) of the hydrogels (Zhang et al., 2015). Furthermore, incorporation of colloidal silica nanoparticles could improve the hemostatic qualities of the hydrogel characterized by reduced clotting (Meddahi-Pellé et al., 2014; Zhang et al., 2015). Crucially, resulting cured porous scaffolds were biodegradable and supported cell infiltration both in vitro and in vivo, and remained stable for at least 8 weeks, without eliciting an immune response. The dependence on UV for curing allows for the materials to be placed and molded in the area of interest (e.g., deep inside the damaged tissue) prior to curing. While this physical barrier prevents loss of fluids and infection, further antimicrobial enhancements have been imparted in the scaffolds by incorporating antimicrobial peptide (AMP) sequences in the ELR structure (da Costa et al., 2015; Shirzaei Sani et al., 2018; Atefyekta et al., 2019). Helping to keep the wound microbe-free, this approach addresses the challenges posed by biomaterial-associated infection, such as the difficulty to treat biofilm adhesion to the material (Atefyekta et al., 2019). Recently, a porous film of an ELR polypeptide, containing an antimicrobial peptide (ABP-CM4) derived from Bombyx mori, produced by solvent casting supported the viability of human fibroblasts and keratinocytes in vitro with good antimicrobial profile against common human pathogens, including Grampositive, Gram-negative bacteria, and filamentous fungi in an ex vivo pig skin model [146]. Similarly, the covalent tethering of antimicrobial peptide RRPRPRPRPWWWW-NH2 (RRP9W4N) into the surface of an ELR-based surface coating endowed antibacterial activity against Staphylococcus epidermidis,
Staphylococcus aureus, and Pseudomonas aeruginosa without affecting the viability, function, and differentiation of human osteosarcoma MG63 cells and human mesenchymal stem cells (hMSCs) (Atefyekta et al., 2019).

In addition to facilitation of early wound closure and antimicrobial properties, ELRs have also been modified with bioactive peptides to facilitate and control the regeneration and remodeling of dermal tissue. Indeed, several peptides that mimic several dermal ECM features relevant for wound healing such as RGD for general cell adhesion and proliferation (Lampe and Heilshorn, 2012; Choi et al., 2016), laminin mimicking YIGSR and IKVAV forms keratinocyte and fibroblast integrin interaction (Lampe and Heilshorn, 2012; Paiva dos Santos et al., 2019), collagen mimicking DGEA and GFOGER (Lampe and Heilshorn, 2012; Luo and Kiick, 2015; Le and Sugawara-Narutaki, 2019), VEGF mimetic peptides (i.e., QK) to promote angiogenesis in vivo, (Andrea et al., 2005; Reddel et al., 2013; Cai et al., 2014; Flora et al., 2019a) REDV for endothelial cell adhesion (Castellanos et al., 2015; González de Torre et al., 2018), and laminin mimetic peptides to improve keratinocyte proliferation and activities have been used in ELRs for dermal applications (Wen et al., 2020). Some ELPs have been reported to display therapeutic effects by enhancing chemotactic activity and inducing fibroblast proliferation, presumably as a result of binding to cell surface heparan sulfate proteoglycan [45]. Moreover, an RGD-containing ELR physically cross-linked with encapsulated cargo adipose stem cells (ASCs) and designed to adapt to the shape of a full-thickness excisional wound in mice accelerated wound closure and reepithelialization without immune rejection and was completely degraded and replaced with newly formed ECM after 7 days (Choi et al., 2016). Similarly, González de Torre et al produced porous electrospun microfiber mats composed of SPAAC-crosslinked RGD-bearing ELRs (González de Torre et al., 2018) that could improve the attachment, spreading, and proliferation of keratinocytes (HaCaT cells) and fibroblasts (HFF-1) in vitro (Choi et al., 2016), suggesting potential efficacy in dermal repair.

Collectively, these examples point to the benefits of incorporating tailored functional peptides to constructs. Indeed, elastin-based materials have started seeing use in clinical applications (Wen et al., 2020). Matriderm and Glyaderm are commercially available dermal substitutes composed of collagen-elastin mixture that are widely used in the treatment full-thickness skin defects such as burn wounds, where the elastin component is credited for enhanced biomechanical stability and elasticity in healed tissue (Pirayesh et al., 2015; Petersen et al., 2016; Wen et al., 2020). In consistency with this, the incorporation of recombinant human tropoelastin (rhTE) into a commercially available dermal substitute, Integra, was noted to enhance dermal regeneration and accelerate angiogenesis in murine and porcine models, with reduced contractures in the latter (Wang et al., 2015). Similarly, the culture of human dermal fibroblasts on tropoelastin-containing Integra resulted in the generation of dense, layered elastic fibers in tunable quantities, regardless of donor age (Annabi et al., 2017a). Recently, two novel scaffolds, methacryloyl-substituted recombinant human tropoelastin (MeTro) biopolymer with 
antimicrobial properties (Annabi et al., 2017a) and a heat-treated tropoelastin construct (HeaTro) (Mithieux et al., 2018) were UVcured on a wet wound into a composite hydrogel (MeTro/ GelMA) and demonstrated improved proliferation and migration of mouse embryonic fibroblast cells and subcutaneous graft uptake (Annabi et al., 2017b).

In a study to understand the optimal pore size and level of cross-linking of Matriderm dermal substitutes, porcine fullthickness wounds in combination with autologous split skin mesh grafts (SSG) were used. Matriderm scaffolds with a pore size of 80 or $100 \mu \mathrm{m}$ resulted in good wound healing after onestage grafting, while larger average pore size $(120 \mu \mathrm{m})$ resulted in more myofibroblasts and foreign body giant cells (FBGCs). In addition, moderate cross-linking resulted in impaired wound healing characterized by more wound contraction, more FBGCs, and increased epidermal thickness compared to no cross-linking. However, vascularization and the number of myofibroblasts were not affected by cross-linking. Surprisingly, the stability of cross-linked scaffolds was not increased in the wound environment, in contrast to in vitro results. The non-cross-linked skin substitute with unidirectional pores allowed one-stage grafting of SSGs, resulting in good wound healing, with only a very mild foreign body reaction (Boekema et al., 2014).

\section{Bone and Cartilage Applications}

Bone integrity, including that of the mineral content and loadbearing quality, is controlled by the activities of the biological content, which includes cells and structural and nonstructural proteins (Alliston, 2014). In this regard, several peptides and proteins have been used to control cell behavior, improve bone accrual (Alliston, 2014; Wang et al., 2017; Mbundi et al., 2018), improve fracture healing, and as coatings of loadbearing (metallic and plastic) implants (Pountos et al., 2016; Wang et al., 2017). Being inherently porous, natural polymer-based biomaterials used are generally endowed with pores. Recently, an injectable mixture of VKVx24-cyclo, HRGD6- $\mathrm{N}_{3}$ (intergrin mimic), and REDV- $\mathrm{N}_{3}$ (elastase labile) ELRs, (all at $75 \mathrm{mg} / \mathrm{ml}$ ) cross-linkable in situ by click chemistry (through -cyclo and azide groups) (Cipriani et al., 2019) produced a scaffold with interconnected pores $(\sim 3-20 \mu \mathrm{m}$ in size) that supported cargo rMSCs cells in vitro and could repair subchondral defects with better collagen II hyaline cartilage regeneration in New Zealand rabbits after 4 months. In this study, the complete degradation of the scaffold was synchronized with regeneration of new bone tissue. In a similar study, stability and mechanical properties of an injectable ELR were improved by combining silk, elastin, and RGD motifs (SELR (EIS) $)_{2}$ (I5R) ${ }_{6}$ ) in the sequence, controlling preannealing treatment and concentration to optimize viscoelasticity toward that of cartilage and pore size $(\sim 10.23 \pm 2.87 \mu \mathrm{m})$ to accommodate chondrocytes (Cipriani et al., 2018). Crucially, in vitro and $e x$ vivo studies demonstrated improved cell activity with characteristic increase in glycosaminoglycan (GAG) and collagen type II (hyaline cartilage), making this hydrogel a suitable candidate for osteochondral repair. Elsewhere, the regulation of the stiffness of an ELR-based porous scaffold
(95.3 and $106.6 \mu \mathrm{m}$ pores, $59.8 \%$ porosity) was used to direct the differentiation of mesenchymal stem cells (MSCs) toward osteogenic and adipogenic lineages (Haugh et al., 2018). Whereas cell adhesive domains (RGD and YIGSR) improved cell infiltration and viability, increasing substrate moduli from 0.5 to 15 and $50 \mathrm{kPa}$ led to an increase in adipogenic and osteogenic differentiation markers.

ELR $T_{t}$ can also be used to deliver cargo xenogeneic cell grafts in bone defect applications. In this regard, the injection and physical cross-linking of an ELR mixture with or without cargo xenogeneic MSCs in New Zealand white rabbit femoral defects showed a $91 \%$ and $47 \%$ increase in osteochondral regeneration after 3 months, without eliciting an immune rejection (Pescador et al., 2017). The improved bone regeneration seen with cargo MSCs can also be achieved by using bioactive peptides, growth factors, and drugs. In this regard, a combination of bone morphogenic protein 2 (BMP-2) mimicking motifs and elastase-labile domains in the ELR backbone showed reciprocal lamellar bone and vascular channels regeneration and scaffold biodegradation in New Zealand rabbits femoral defects (2017). Elsewhere, ELRs (IK24, VK24, REDV, HSS1, and HSS3) were developed to induce mineralization akin to natural intrafibrillar mineralization (Li et al., 2017). However, although HSS1 and HSS3 contained human salivary sequence (SNa15) known to promote the nucleation and growth of calcium phosphate solutions into hydroxyapatite nanocrystals, poorly homogenous crystallization was achieved with these two recombinamers, in comparison to IK24 and VK24 (Li et al., 2017). This suggests that particular attention should be paid to how the chosen biological motifs affect structural and intended biological properties. One way of avoiding this involves tethering bioactive motifs and molecules to the side functional groups of the ELRs or mixing (complexing) ELRs with other bioactive polymers. Indeed, the tethering of hyaluronic acid to EPL (ELP-HA) has been reported to improve chondrocyte viability and activity with characteristic improved hyaline cartilage regeneration and cartilage-specific matrix sulfated glycosaminoglycan (sGAG) deposition (Zhu et al., 2017). In another study, a film of a polymer blend containing rat tail collagen I, Bombyx mori fibroin, and ELR at a $6: 3: 1(\mathrm{~m} / \mathrm{m})$ ratio micropatterned on polydimethylsiloxane (PDMS) was used with human fibroblast and ADSCs to stimulate controlled anisotropic osteogenesis after 28 days in culture. Indeed, cell alignment followed microchannel patterned to mimic natural bone tissue organization. Moreover, ADSC proliferation on the films was 2-fold higher than that of fibroblasts, and an increase in mineralization and ECM secretion collated with increased mechanical properties along the microchannel (Sayin et al., 2017).

\section{Dental Applications}

In dental applications, ELRs have been used for interventions such as enamel regeneration, alveolar bone repair, tooth replacement, and canal filling. Studies have reported the ELPassisted enamel mineralization to recapitulate natural hierarchical hydroxyapatite structure. In this regard, a composite of a glutamic acid-rich ELP (E125) and amorphous 
calcium phosphate (ACP) showed quick mineralization (within $12 \mathrm{~h}$ ) with mechanical performance as determined by Knoop microhardness and nanoindentation that were similar to other artificial enamel (Zhou et al., 2018). To address the draw backs associated with widely used calcium phosphate cements (CPCs) such as poor mechanical properties and poor anti-washout capability in biological fluids, a glutamic acid-rich ELP (V125E8) was mixed CPC. V125E8 incorporation produced a denser microstructure with decreased porosity and a more compact surface with a characteristic increase in microhardness (two- to seven-fold) and compressive strength (10-fold), as well as improved washout resistance (3-fold). The increase in the mechanical strength of these composites is attributed to high-affinity interactions between the carboxylic acids in the glutamic acid in ELPs and calcium ions, reinforcing the inner binding of the crystal (Jang et al., 2018).

In other approaches exploiting the ELP order-disorder interplay with ions to produce hierarchically ordered mineralized structures in dental applications, ELPs containing lysine for cross-linking and the SNa15, a mineralization promoter domain, were mixed with fluorapatite (Shuturminska et al., 2017; Elsharkawy et al., 2018) or calcium phosphate (Misbah et al., 2017) to produce hierarchically ordered membranes. Fluorapatite mineralization resulted in an hierarchically organized pherulite-like morphology with a characteristic maltese cross-pattern (nucleating sites) and aligned nanocrystals of fluorapatite (Elsharkawy et al., 2018). In these systems, mineralizationetched and rough surfaces of human dentin was completed in 8 days and demonstrated resistance against acid attack that was comparable to dental enamel after $15 \mathrm{~min}$. The mechanical properties of the resulting mineralized membranes reported values higher than bone and dentine and almost half of dental enamel. To control the physicochemical parameters, material hardness could be reduced by reducing the amount of cross-linker, the amount of mineralization could be increased by increasing acidic charges (i.e., glutamic acid amino acid) on ELR backbone, and the size of the hierarchical structure could be increased by maintaining a constant $\mathrm{pH}$ during mineralization (Elsharkawy et al., 2018). In studies with calcium phosphate, a poorly ordered cauliflower-like hydroxyapatite structures observed in the absence of $\mathrm{SNa} 15$ domains was replaced by an ordered plate-like structures where SNa15 domains were present (Misbah et al., 2017). In addition to providing crystallization promotion stimuli, ELR incorporation provides a structural matrix around which mineral crystals form and grow.

\section{SUMMARY}

Porous biomaterials are of significant interest in a variety of tissue engineering and biomedical applications as they not only enable the diffusion of nutrients, gases, and waste but also promote cell adhesion, tissue infiltration, host integration with improved biocompatibility, and the development of complex structures such as vasculature and the ECM. Given ECM heterogeneity across and within different tissues, a high degree of fabrication controls over design architectures, from molecular through nano- and micro- to macroscale levels, is important to meet the myriad tissue engineering and clinical application needs. In this regard, elastin-based polymers such as ELPs and ELRs have gained popularity owing to their inherent unique elastic recoil properties and physicochemical properties that can be controlled at a molecular level to endow bespoke properties suitable for the desired scaffold fabrication method and target biomaterial architectural features. For instance, using one or a combination of the porous scaffold fabrication methods discussed in this review, pore size and porosity can be tuned to support the attachment and activities of a particular cell type and the amount of surface area tuned to provide an adequate platform for imparting both biochemical and topographical cues. Furthermore, the degree of control of scaffold features such as pore size and porosity afforded by scaffold fabrication parameters such as temperature, polymer solvent, solute concentration, cooling rate, solvents, and porogen type can be further enhanced by varying ELR amino acid sequence to control parameters such as polymer molecular weight, charge, solubility, transition temperatures, biocompatibility, and biodegradation.

While different studies have shown that different cell types have different optimal pore size range and porosity for viability and activity, there is variation in the actual ideal pore size and porosity range reported for the same cell type or in vivo model by different researchers working with different polymers (i.e., collagen, chitosan, and ELP/ELRs). This suggest that ideal pore and porosity for a given cell type and or polymer-based scaffold should not be generally assumed, but rather carefully characterized, tested, and optimized for the intended application. This is partly because cells do not only respond to the physical cure provided by the matrix within which they are compartmentalized but also the biochemical cues provided by the scaffold polymer. For instance, whereas nanoscale texture (i.e., from nanofiber porous scaffold) helps to recapitulate the ECM surface morphology of proteins (i.e., collagen and elastin) that support cells and tissue organization, and microscale porosity promotes nutrient transfer, cell migration, and proliferation, leading to host integration, variation in ELR-polymer chemistry can affect cell activities differently. Furthermore, inherent parameters such as elasticity and Tt-dependent swelling, which can increase or reduce scaffold pore size and volume, and the ability to accommodate enzyme-labile domains enables the development of scaffolds with physical features that can adapt to and support the dynamism of newly encroaching cells and ECM while biodegrading in a reciprocal manner. These ELR qualities and the inherent biocompatibility and amenability to functionalization to confer specific novel biological functionalities, and the temperature-dependent phase transition that can be fine-tuned to allow ELR gelation under physiological conditions makes an ideal flexible technological platform for the advancement of regenerative 
medicine and tissue engineering. However, while many technological advances have been made in the development and application of tropoelastin and ELP/ELR-based biomaterials, as evidenced by the sheer variety of constructs being investigated and those already in use, much work remains for their broader translation to the market and clinical applications. If safety and efficacy of tropoelastin and ELP/ELR-based materials can be demonstrated through more studies, including clinical trials in various biomedical applications, this flexible technological platform may open the door to using these dynamic materials to treat a wide range of conditions. Indeed, the success of the simple collagen-elastin blends (i.e., Matriderm and Glyaderm) as well as MeTro and HeaTro hydrogels are good examples of the potential and poise of ELPs and their recombinant derivatives to render the next era of health care and pharmaceutical science more tangible.

\section{REFERENCES}

Abbasi, N., Hamlet, S., Love, R., M., and Nguyen, N.-T. (2020). Porous scaffolds for bone regeneration. J. Sci. Adv. Mater. Devices 5, 1-9. doi:10.1016/j.jsamd.2020. 01.007

Acosta, S., Quintanilla-Sierra, L., Mbundi, L., Reboto, V., and Rodríguez-Cabello, J.-C. (2020). Elastin-like recombinamers: deconstructing and recapitulating the functionality of extracellular matrix proteins using recombinant protein polymers. Adv. Funct. Mater. 30, 1909050. doi:10.1002/adfm.201909050

Aguilar-De-Leyva, Á., Linares, V., Casas, M., and Caraballo, I. (2020). 3D printed drug delivery systems based on natural products. Pharmaceutics 12, 620. doi:10. 3390/pharmaceutics 12070620

Akande, W., Mikhalovska, L., James, S., and Mikhalovsky, S. (2015). Affinity binding macroporous monolithic cryogel as a matrix for extracorporeal apheresis medical devices. Int. J. Biomed. Mater. Res. 3, 56-63. doi:10. 11648/j.ijbmr.20150305.11

Akbarzadeh, R., and Yousefi, A. M. (2014). Effects of processing parameters in thermally induced phase separation technique on porous architecture of scaffolds for bone tissue engineering. J. Biomed. Mater. Res. B. Appl. Biomater. 102, 1304-1315. doi:10.1002/jbm.b.33101

Alliston, T. (2014). Biological regulation of bone quality. Curr. Osteoporos. Rep. 12, 366-375. doi:10.1007/s11914-014-0213-4

Almine, J. F., Wise, S. G., and Weiss, A. S. (2012). Elastin signaling in wound repair. Birth Defects Res C Embryo Today 96, 248-257. doi:10.1002/bdrc.21016

Andrea, L., Domenico, I. G., Fattorusso, R., Sorriento, D., Carannante, C., Capasso, D., et al. (2005). Targeting angiogenesis: structural characterization and biological properties of a de novo engineered VEGF mimicking peptide. Proc. Natl. Acad. Sci. U.S.A. 102, 14215. doi:10.1073/pnas.0505047102

Annabi, N., Fathi, A., Mithieux, S. M., Martens, P., Weiss, A. S., and Dehghani, F. (2011a). The effect of elastin on chondrocyte adhesion and proliferation on poly ( $\varepsilon$-caprolactone)/elastin composites. Biomaterials 32, 1517-1525. doi:10.1016/j. biomaterials.2010.10.024

Annabi, N., Mithieux, S. M., Boughton, E. A., Ruys, A. J., Weiss, A. S., and Dehghani, F. (2009a). Synthesis of highly porous crosslinked elastin hydrogels and their interaction with fibroblasts in vitro. Biomaterials 30, 4550-4557. doi:10.1016/j.biomaterials.2009.05.014

Annabi, N., Mithieux, S. M., Camci-Unal, G., Dokmeci, M. R., Weiss, A. S., and Khademhosseini, A. (2013a). Elastomeric recombinant protein-based biomaterials. Biochem. Eng. J 77, 110-118. doi:10.1016/j.bej.2013.05.006

Annabi, N., Mithieux, S. M., Weiss, A. S., and Dehghani, F. (2010). Cross-linked open-pore elastic hydrogels based on tropoelastin, elastin and high pressure CO2. Biomaterials 31, 1655-1665. doi:10.1016/j.biomaterials.2009.11.051

Annabi, N., Mithieux, S. M., Weiss, A. S., and Dehghani, F. (2009b). The fabrication of elastin-based hydrogels using high pressure $\mathrm{CO}(2)$. Biomaterials 30, 1-7. doi:10.1016/j.biomaterials.2008.09.031

\section{AUTHOR CONTRIBUTIONS}

LM has written the review, and along with MG-P, FG-P, DJ-G, contributed to the conceptualization, literature search, original sections drafting, figure and table generation, and draft reviewing. JR-C contributed to the conceptualization, supervision, and sourcing funding for the team.

\section{FUNDING}

The authors are grateful for the funding from the Spanish Government (MAT2016-78903-R, RTI2018-096320-B-C22, FPU15-00448, FPU16-04015, PID2019-110709RB-100), Junta de Castilla y León (VA317P18), Interreg V España Portugal POCTEP (0624_2IQBIONEURO_6_E) and Centro en Red de Medicina Regenerativa y Terapia Celular de Castilla y León.

Annabi, N., Mithieux, S. M., Zorlutuna, P., Camci-Unal, G., Weiss, A. S., and Khademhosseini, A. (2013b). Engineered cell-laden human protein-based elastomer. Biomaterials 34, 5496-5505. doi:10.1016/j.biomaterials.2013.03.076

Annabi, N., Rana, D., Shirzaei Sani, E., Portillo-Lara, R., Gifford, J. L., Fares, M. M., et al. (2017a). Engineering a sprayable and elastic hydrogel adhesive with antimicrobial properties for wound healing. Biomaterials 139, 229-243. doi:10. 1016/j.biomaterials.2017.05.011

Annabi, N., Shin, S., Tamayol, A., Miscuglio, M., Bakooshli, M., Assmann, A., et al. (2016). Highly elastic and conductive human-based protein hybrid hydrogels. Adv. Mater Weinheim 28, 40-49. doi:10.1002/adma.201503255

Annabi, N., Zhang, Y. N., Assmann, A., Sani, E., Cheng, G., Lassaletta, A. D., et al. (2017b). Engineering a highly elastic human protein-based sealant for surgical applications. Sci. Transl. Med. 9, eaai7466. doi:10.1126/scitranslmed.aai7466

Annabi, N., Fathi, A., Mithieux, S., M., Weiss, A., S., and Dehghani, F. (2011b). Fabrication of porous PCL/elastin composite scaffolds for tissue engineering applications. J. Supercrit. Fluids 59, 157-167. doi:10.1016/j.supflu.2011. 06.010

Annabi, N. (2012). "Porous biomaterials," in Integrated biomaterials for biomedical technology. Editors R. Murugan, T. Ashutosh, R. Seeram, and K. Hisatoshi (Beverly, MA: Scrivener Publishing LLC), 35-65.

Arias, F., Javier, M. S., Arturo, I.-F., Maria Jesus, P., and Sofía, S. (2018). Elastin-like recombinamers as smart drug delivery systems. Curr. Drug Targets 19, 360-379. doi:10.2174/1389450117666160201114617

Atefyekta, S., Pihl, M., Lindsay, C., Heilshorn, S. C., and Andersson, M. (2019). Antibiofilm elastin-like polypeptide coatings: functionality, stability, and selectivity. Acta Biomater 83, 245-256. doi:10.1016/j.actbio.2018.10.039

Bač́ková, L., Novotná, K., and Pařízek, M. (2014). Polysaccharides as cell carriers for tissue engineering: the use of cellulose in vascular wall reconstruction. Physiol. Res. 63, S29-S47. doi:10.33549/physiolres.932644

Barbetta, A., Gumiero, A., Pecci, R., Bedini, R., and Dentini, M. (2009). Gas-inLiquid foam templating as a method for the production of highly porous scaffolds. Biomacromolecules 10, 3188-3192. doi:10.1021/bm901051c

Barbetta, A., Rizzitelli, G., Bedini, R., Pecci, R., and Dentini, M. (2010). Porous gelatin hydrogels by gas-in-liquid foam templating. Soft Matter 6, 1785-1792. doi:10.1039/B920049E

Bedell-Hogan, D., Trackman, P., Abrams, W., Rosenbloom, J., and Kagan, H. (1993). Oxidation, cross-linking, and insolubilization of recombinant tropoelastin by purified lysyl oxidase. J. Biol. Chem. 268, 10345-10350.

Belsom, A., and Rappsilber, J. (2021). Anatomy of a crosslinker. Curr. Opin. Chem. Biol. 60, 39-46. doi:10.1016/j.cbpa.2020.07.008

Berillo, D. A., Caplin, J. L., Cundy, A. B., and Savina, I. N. (2019). A cryogel-based bioreactor for water treatment applications. Water Res. 153, 324-334. doi:10. 1016/j.watres.2019.01.028

Bernacki, J. P., and Murphy, R. M. (2011). Length-dependent aggregation of uninterrupted polyalanine peptides. Biochemistry 50, 9200-9211. doi:10.1021/ bi201155g 
Betre, H., Setton, L. A., Meyer, D. E., and Chilkoti, A. (2002). Characterization of a genetically engineered elastin-like polypeptide for cartilaginous tissue repair. Biomacromolecules 3, 910-916. doi:10.1021/bm0255037

Bittner, S. M., Guo, J. L., and Mikos, A. G. (2018). Spatiotemporal control of growth factors in three-dimensional printed scaffolds. Bioprinting 12, e00032. doi:10. 1016/j.bprint.2018.e00032

Boekema, B., Vlig, M., Olde Damink, L., Middelkoop, E., Eummelen, L., Bühren, A. V., et al. (2014). Effect of pore size and cross-linking of a novel collagen-elastin dermal substitute on wound healing. J. Mater. Sci. Mater. Med. 25, 423-433. doi:10.1007/s10856-013-5075-2

Bonfield, W. (2005). Designing porous scaffolds for tissue engineering. Philos. Trans. A Math Phys. Eng. Sci. 364, 227-232. doi:10.1098/rsta.2005.1692

Borislav, Z., Jiř́, Č., Martin, Š., and Josef, J. (2007). Pore classification in the characterization of porous materials: a perspective. Open Chem. 5, 385-395. doi:10.2478/s11532-007-0017-9

Brennan, M., Kilbride, B. F., Wilker, J. J., and Liu, J. C. (2017). A bioinspired elastin-based protein for a cytocompatible underwater adhesive. Biomaterials 124, 116-125. doi:10.1016/j.biomaterials.2017.01.034

Broekelmann, T. J., Kozel, B. A., Ishibashi, H., Werneck, C. C., Keeley, F. W., Zhang, L., et al. (2005). Tropoelastin interacts with cell-surface glycosaminoglycans via its $\mathrm{COOH}$-terminal domain. J. Biol. Chem. 280, 40939-40947. doi:10.1074/jbc.M507309200

Bryant, S. J., Cuy, J. L., Hauch, K. D., and Ratner, B. D. (2007). Photo-patterning of porous hydrogels for tissue engineering. Biomaterials 28, 2978-2986. doi:10. 1016/j.biomaterials.2006.11.033

Busquets, R., Ivanov, A. E., Mbundi, L., Hörberg, S., Kozynchenko, O. P., Cragg, P. J., et al. (2016). Carbon-cryogel hierarchical composites as effective and scalable filters for removal of trace organic pollutants from water. J. Environ. Manag. 182, 141-148. doi:10.1016/j.jenvman.2016.07.061

Buttafoco, L., Engbers-Buijtenhuijs, P., Poot, A. A., Dijkstra, P. J., Daamen, W. F., Van Kuppevelt, T. H., et al. (2006). First steps towards tissue engineering of small-diameter blood vessels: preparation of flat scaffolds of collagen and elastin by means of freeze drying. J. Biomed. Mater. Res. B Appl. Biomater 77, 357-368. doi:10.1002/jbm.b.30444

Cai, L., Dinh, C. B., and Heilshorn, S. C. (2014). One-pot synthesis of elastin-like polypeptide hydrogels with grafted VEGF-mimetic peptides. Biomater Sci. 2, 757-765. doi:10.1039/C3BM60293A

Castellanos, M., Zenses, A. S., Grau, A., Rodríguez-Cabello, J. C., Gil, F., Manero, J., et al. (2015). Biofunctionalization of REDV elastin-like recombinamers improves endothelialization on $\mathrm{CoCr}$ alloy surfaces for cardiovascular applications. Colloids Surf. B Biointerfaces 127, 22-32. doi:10.1016/j.colsurfb. 2014.12.056

Chandy, T., Rao, G. H., Wilson, R. F., and Das, G. S. (2003). The development of porous alginate/elastin/PEG composite matrix for cardiovascular engineering. J. Biomater. Appl. 17, 287-301. doi:10.1177/0885328203017004004

Chen, L., Zhou, M.-L., Qian, Z.-G., Kaplan, D., L., and Xia, X.-X. (2017). Fabrication of protein films from genetically engineered silk-elastin-like proteins by controlled cross-linking. ACS Biomater. Sci. Eng. 3, 335-341. doi:10.1021/acsbiomaterials.6b00794

Choi, S. K., Park, J. K., Kim, J. H., Lee, K. M., Kim, E., Jeong, K. S., et al. (2016). Integrin-binding elastin-like polypeptide as an in situ gelling delivery matrix enhances the therapeutic efficacy of adipose stem cells in healing full-thickness cutaneous wounds. J. Contr. Release 237, 89-100. doi:10.1016/j.jconrel.2016. 07.006

Christina, F., Mohammad, R. K.-M., Jeffrey, B., Joseph, P. V., Robert, L., and Yadong, W. (2005). Endothelialized microvasculature based on a biodegradable elastomer. Tissue Eng. 11, 302-309. doi:10.1089/ten.2005.11.302

Cima, L. G., Vacanti, J. P., Vacanti, C., Ingber, D., Mooney, D., and Langer, R. (1991). Tissue engineering by cell transplantation using degradable polymer substrates. J. Biomech. Eng. 113, 143-151. doi:10.1115/1.2891228

Cipriani, F., Ariño Palao, B., Gonzalez De Torre, I., Vega Castrillo, A., Aguado Hernández, H. J., Alonso Rodrigo, M., et al. (2019). An elastin-like recombinamer-based bioactive hydrogel embedded with mesenchymal stromal cells as an injectable scaffold for osteochondral repair. Regen Biomater 6, 335-347. doi:10.1093/rb/rbz023

Cipriani, F., Krüger, M., Gonzalez De Torre, I., Sierra, L., Quintanilla, R. M., Alonso, K. L., et al. (2018). Cartilage regeneration in preannealed silk elastinlike co-recombinamers injectable hydrogel embedded with mature chondrocytes in an ex vivo culture platform. Biomacromolecules 19, 4333-4347. doi:10.1021/acs.biomac.8b01211

Coletta, D. J., Ibáñez-Fonseca, A., Missana, L. R., Jammal, M. V., Vitelli, E. J., Aimone, M., et al. (2017). Bone regeneration mediated by a bioactive and biodegradable extracellular matrix-like hydrogel based on elastin-like recombinamers. Tissue Eng. 23, 1361-1371. doi:10.1089/ten.TEA.2017.0047

Colosi, C., Costantini, M., Barbetta, A., Pecci, R., Bedini, R., and Dentini, M. (2013). Morphological comparison of PVA scaffolds obtained by gas foaming and microfluidic foaming techniques. Langmuir 29, 82-91. doi:10.1021/la303788z

Da Costa, A., Machado, R., Ribeiro, A., Collins, T., Thiagarajan, V., NevesPetersen, M., et al. (2015). Development of elastin-like recombinamer films with antimicrobial activity. Biomacromolecules 16, 625-635. doi:10.1021/ bm5016706

Da Costa, A., Pereira, A. M., Gomes, A. C., Rodriguez-Cabello, J. C., Sencadas, V., Casal, M., et al. (2017). Single step fabrication of antimicrobial fibre mats from a bioengineered protein-based polymer. Biomed. Mater. 12, 045011. doi:10.1088/ 1748-605X/aa7104

Debelle, L., and Tamburro, A. M. (1999). Elastin: molecular description and function. Int. J. Biochem. Cell Biol. 31, 261-272. doi:10.1016/s1357-2725(98) 00098-3

Dehghani, F., and Annabi, N. (2011). Engineering porous scaffolds using gas-based techniques. Curr. Opin. Biotechnol. 22, 661-666. doi:10.1016/j.copbio.2011. 04.005

Detsch, R., Will, J., Hum, J., Roether, J. A., and Boccaccini, A. R. (2018). "Biomaterials," in Cell culture technology. Editors C. Kasper, V. Charwat, and A. Lavrentieva (Cham, Switzerland: Springer International Publishing)), 91-105.

Dimarco, R. L., Dewi, R. E., Bernal, G., Kuo, C., and Heilshorn, S. C. (2015). Protein-engineered scaffolds for in vitro 3D culture of primary adult intestinal organoids. Biomater. Sci. 3, 1376-1385. doi:10.1039/c5bm00108k

Draghi, L., Resta, S., Pirozzolo, M. G., and Tanzi, M. C. (2005). Microspheres leaching for scaffold porosity control. J. Mater. Sci. Mater. Med. 16, 1093-1097. doi:10.1007/s10856-005-4711-x

Duca, L., Floquet, N., Alix, A. J., Haye, B., and Debelle, L. (2004). Elastin as a matrikine. Crit. Rev. Oncol. Hematol. 49, 235-244. doi:10.1016/j.critrevonc. 2003.09.007

Eisenbarth, E. (2007). Biomaterials for tissue engineering. Adv. Eng. Mater. 9, 1051-1060. doi:10.1002/adem.200700287

Elowsson, L., Kirsebom, H., Carmignac, V., Mattiasson, B., and Durbeej, M. (2013). Evaluation of macroporous blood and plasma scaffolds for skeletal muscle tissue engineering. Biomater. Sci. 1, 402-410. doi:10.1039/c2bm00054g

Elsharkawy, S., Al-Jawad, M., Pantano, M. F., Tejeda-Montes, E., Mehta, K., Jamal, H., et al. (2018). Protein disorder-order interplay to guide the growth of hierarchical mineralized structures. Nat. Commun. 9, 2145. doi:10.1038/ s41467-018-04319-0

Fernández-Colino, A., Arias, F., Javier, A. M., and Rodríguez-Cabello, J.-C. (2015). Amphiphilic elastin-like block co-recombinamers containing leucine zippers: cooperative interplay between both domains results in injectable and stable hydrogels. Biomacromolecules 16, 3389-3398. doi:10.1021/acs.biomac.5b01103

Fernández-Colino, A., Arias, F., Javier, A. M., and Rodríguez-Cabello, J.-C. (2014). Self-organized ECM-mimetic model based on an amphiphilic multiblock silkelastin-like corecombinamer with a concomitant dual physical gelation process. Biomacromolecules 15, 3781-3793. doi:10.1021/bm501051t

Fernández-Colino, A., Wolf, F., Keijdener, H., Rütten, S., Schmitz-Rode, T., Jockenhoevel, S., et al. (2018). Macroporous click-elastin-like hydrogels for tissue engineering applications. Mater. Sci. Eng. C 88, 140-147. doi:10.1016/j. msec.2018.03.013

Fernández-Colino, A., Wolf, F., Moreira, R., Rütten, S., Schmitz-Rode, T., Rodríguez-Cabello, J.-C., et al. (2019a). Layer-by-layer biofabrication of coronary covered stents with clickable elastin-like recombinamers. Eur. Polym. J. 121, 109334. doi:10.1016/j.eurpolymj.2019.109334

Fernández-Colino, A., Wolf, F., Rütten, S., Schmitz-Rode, T., Rodríguez-Cabello, J.-C., Jockenhoevel, S., et al. (2019b). Small caliber compliant vascular grafts based on elastin-like recombinamers for in situ tissue engineering. Front. Bioeng. Biotech. 7, 340. doi:10.3389/fbioe.2019.00340

Figoli, A. (2016). "Thermally induced phase separation (TIPS) for membrane preparation," in Encyclopedia of membranes. Editors E. Drioli and L. Giorno (Berlin, Heidelberg: Springer Berlin Heidelberg)), 1-2. 
Flora, T., de Torre, I., Alonso, M., and Rodríguez-Cabello, J. C. (2019a). Tethering QK peptide to enhance angiogenesis in elastin-like recombinamer (ELR) hydrogels. J. Mater. Sci. Mater. Med. 30, 30. doi:10.1007/s10856-019-6232-z

Flora, T., González de Torre, I., Alonso, M., and Rodríguez-Cabello, J. C. (2019b). Use of proteolytic sequences with different cleavage kinetics as a way to generate hydrogels with preprogrammed cell-infiltration patterns imparted over their given 3D spatial structure. Biofabrication 11, 035008. doi:10.1088/1758-5090/ab10a5

Fu, H., Grimsley, G. R., Razvi, A., Scholtz, J., Pace, C. N., Pace, C., et al. (2009). Increasing protein stability by improving beta-turns. Proteins 77, 491-498. doi:10.1002/prot.22509

Girotti, A., Fernández-Colino, A., López, I. M., Rodríguez-Cabello, J. C., and Arias, F. J. (2011). Elastin-like recombinamers: biosynthetic strategies and biotechnological applications. Biotechnol. J 6, 1174-1186. doi:10.1002/biot. 201100116

Girotti, A., Reguera, J., Rodríguez-Cabello, J. C., Arias, F., Alonso, M., and Matestera, A. (2004b). Design and bioproduction of a recombinant multi(bio)functional elastin-like protein polymer containing cell adhesion sequences for tissue engineering purposes. J. Mater. Sci. Mater. Med. 15, 479-484. doi:10.1023/b:jmsm.0000021124.58688.7a

Girotti, A., Reguera, J., Arias, F., Javier, Alonso, M., Testera, A. M., and RodríguezCabello, J.-C. (2004a). Influence of the molecular weight on the inverse temperature transition of a model genetically engineered elastin-like $\mathrm{pH}$ responsive polymer. Macromolecules 37, 3396-3400. doi:10.1021/ma035603k

Gong, Y., Ma, Z., Zhou, Q., Li, J., Gao, C., and Shen, J. (2008). Poly(lactic acid) scaffold fabricated by gelatin particle leaching has good biocompatibility for chondrogenesis. J. Biomater. Sci. Polym. Ed. 19, 207-221. doi:10.1163/ 156856208783432453

Gonzalez De Torre, I., Alonso, M., and Rodríguez-Cabello, J. C. (2020). Elastinbased materials: promising candidates for cardiac tissue regeneration. Front Bioeng Biotechnol. 8, 657. doi:10.3389/fbioe.2020.00657

González de Torre, I., Santos, M., Quintanilla, L., Testera, A., Alonso, M., and Rodríguez Cabello, J. C. (2014). Elastin-like recombinamer catalyst-free click gels: characterization of poroelastic and intrinsic viscoelastic properties. Acta Biomater 10, 2495-2505. doi:10.1016/j.actbio.2014.02.006

González de Torre, I., Wolf, F., Santos, M., Rongen, L., Alonso, M., Jockenhoevel, S., et al. (2015). Elastin-like recombinamer-covered stents: towards a fully biocompatible and non-thrombogenic device for cardiovascular diseases. Acta Biomater 12, 146-155. doi:10.1016/j.actbio.2014.10.029

Gonzalez De Torre, I., Weber, M., Quintanilla, L., Alonso, M., Jockenhoevel, S., Rodríguez Cabello, J. C., et al. (2016). Hybrid elastin-like recombinamer-fibrin gels: physical characterization and in vitro evaluation for cardiovascular tissue engineering applications. Biomater Sci. 4, 1361-1370. doi:10.1039/c6bm00300a

González De Torre, I., Ibáñez-Fonseca, A., Quintanilla, L., Alonso, M., and Rodríguez-Cabello, J.-C. (2018). Random and oriented electrospun fibers based on a multicomponent, in situ clickable elastin-like recombinamer system for dermal tissue engineering. Acta Biomater 72, 137-149. doi:10. 1016/j.actbio.2018.03.027

González-Pérez, M., González De Torre, I., Alonso, M., and Rodríguez-Cabello, J. C. (2020). Controlled production of elastin-like recombinamer polymerbased membranes at a liquid-liquid interface by click chemistry. Biomacromolecules 21, 4149-4158. doi:10.1021/acs.biomac.0c00939

Gonzalez-Valdivieso, J., Girotti, A., Muñoz, R., Rodríguez-Cabello, J. C., and Arias, F. J. (2019). Self-assembling ELR-based nanoparticles as smart drug-delivery systems modulating cellular growth via akt. Biomacromolecules 20, 1996-2007. doi:10.1021/acs.biomac.9b00206

Gorth, D., and Webster, T., J. (2011). "10 - matrices for tissue engineering and regenerative medicine," in Biomaterials for artificial organs. Editors M. Lysaght and T. J. Webster (Sawston, CA: Woodhead Publishing), 270-286.

Guarino, V., and Ambrosio, L. (2014). "2 - properties of biomedical foams for tissue engineering applications," in Biomedical foams for tissue engineering applications. Editor P.A. Netti (Sawston, CA: Woodhead Publishing), 40-70.

Gun'ko, V. M., Savina, I. N., and Mikhalovsky, S. V. (2013). Cryogels: morphological, structural and adsorption characterisation. Adv. Colloid Interface Sci. 187-188, 1-46. doi:10.1016/j.cis.2012.11.001

Han, J., Lazarovici, P., Pomerantz, C., Chen, X., Wei, Y., and Lelkes, P. I. (2011). Co-electrospun blends of PLGA, gelatin, and elastin as potential nonthrombogenic scaffolds for vascular tissue engineering. Biomacromolecules 12, 399-408. doi:10.1021/bm101149r
Hao, Y., Fowler, E. W., and Jia, X. (2017). Chemical synthesis of biomimetic hydrogels for tissue engineering. Polym. Int. 66, 1787-1799. doi:10.1002/pi. 5407

Haugh, M. G., Vaughan, T. J., Madl, C. M., Raftery, R. M., Mcnamara, L. M., O'brien, F. J., et al. (2018). Investigating the interplay between substrate stiffness and ligand chemistry in directing mesenchymal stem cell differentiation within 3D macro-porous substrates. Biomaterials 171, 23-33. doi:10.1016/j. biomaterials.2018.04.026

Hench, L. L. (1998). Biomaterials: a forecast for the future. Biomaterials 19, 1419-1423. doi:10.1016/s0142-9612(98)00133-1

Henderson, T. M. A., Ladewig, K., Haylock, D. N., McLean, K. M., and O'Connor, A. J. (2013). Cryogels for biomedical applications. J. Mater. Chem. B 1, 2682-2695. doi:10.1039/c3tb20280a

Heydarkhan-Hagvall, S., Schenke-Layland, K., Dhanasopon, A., Rofail, F., Smith, H., Wu, B. M., et al. (2008). Three-dimensional electrospun ECM-based hybrid scaffolds for cardiovascular tissue engineering. Biomaterials 29, 2907-2914. doi:10.1016/j.biomaterials.2008.03.034

Hing, K., Annaz, B., Saeed, S., Revell, P., and Buckland, T. (2005). Microporosity enhances bioactivity of synthetic bone graft substitutes. J. Mater. Sci. Mater. Med 16, 467-475. doi:10.1007/s10856-005-6988-1

Hirai, M., Ohbayashi, T., Horiguchi, M., Okawa, K., Hagiwara, A., Chien, K. R., et al. (2007). Fibulin-5/DANCE has an elastogenic organizer activity that is abrogated by proteolytic cleavage in vivo. J. Cell Biol. 176, 1061-1071. doi:10. 1083/jcb.200611026

Hollister, S. J. (2005). Porous scaffold design for tissue engineering. Nat. Mater. 4, 518. doi:10.1038/nmat1421

Hu, C., Tercero, C., Ikeda, S., Nakajima, M., Tajima, H., Shen, Y., et al. (2013). Biodegradable porous sheet-like scaffolds for soft-tissue engineering using a combined particulate leaching of salt particles and magnetic sugar particles. J. Biosci. Bioeng. 116, 126-131. doi:10.1016/j.jbiosc.2013.01.011

Huang, W., Tarakanova, A., Dinjaski, N., Wang, Q., Xia, X., Chen, Y., et al. (2016). Design of multistimuli responsive hydrogels using integrated modeling and genetically engineered silk-elastin-like proteins. Adv. Funct. Mater. 26, 4113-4123. doi:10.1002/adfm.201600236

Hubbell, J. A., Massia, S. P., Desai, N. P., and Drumheller, P. D. (1991). Endothelial cell-selective materials for tissue engineering in the vascular graft via a new receptor. Biotechnology 9, 568-572. doi:10.1038/nbt0691-568

Ibáñez-Fonseca, A., Flora, T., Acosta, S., and Rodríguez-Cabello, J.-C. (2019). Trends in the design and use of elastin-like recombinamers as biomaterials. Matrix Biol. 84, 111-126. doi:10.1016/j.matbio.2019.07.003

Ibáñez-Fonseca, A., Orbanic, D., Arias, F., Javier, A. M., Zeugolis, D., I., and Rodríguez-Cabello, J.-C. (2020a). Influence of the thermodynamic and kinetic control of self-assembly on the microstructure evolution of silkelastin-like recombinamer hydrogels. Small 16, 2001244. doi:10.1002/smll. 202001244

Ibáñez-Fonseca, A., Santiago, M., Silvia, G. D. B., Darya, C. B., Benedicta, V. C., Aurelio, Á. B., et al. (2020b). Elastin-like recombinamer hydrogels for improved skeletal muscle healing through modulation of macrophage polarization. Front. Bioeng. Biotech. 8, 413. doi:10.3389/fbioe.2020.00413

Ingavle, G., Baillie, L., Davies, N., Beaton, N., Zheng, Y., Mikhalovsky, S., et al. (2018). Bioinspired detoxification of blood: the efficient removal of anthrax toxin protective antigen using an extracorporeal macroporous adsorbent device. Sci. Rep. 8, 7518. doi:10.1038/s41598-018-25678-0

Jafarkhani, M., Salehi, Z., Aidun, A., and Shokrgozar, M. A. (2019). Bioprinting in vascularization strategies. Iran. Biomed. J 23, 9-20. doi:10.29252/.23.1.9

Jain, E., Karande, A. A., and Kumar, A. (2011). Supermacroporous polymer-based cryogel bioreactor for monoclonal antibody production in continuous culture using hybridoma cells. Biotechnol. Prog. 27, 170-180. doi:10.1002/btpr.497

Jain, E., and Kumar, A. (2013). Disposable polymeric cryogel bioreactor matrix for therapeutic protein production. Nat. Protoc. 8, 821-835. doi:10.1038/nprot. 2013.027

Jang, J. H., Shin, S., Kim, H. J., Jeong, J., Jin, H. E., Desai, M. S., et al. (2018). Improvement of physical properties of calcium phosphate cement by elastinlike polypeptide supplementation. Sci. Rep. 8, 5216. doi:10.1038/s41598-01823577-y

Jensen, S. A., Vrhovski, B., Weiss, A., and , S. (2000). Domain 26 of tropoelastin plays a dominant role in association by coacervation. J. Biol. Chem. 275, 28449-28454. doi:10.1074/jbc.M004265200 
Johnson, B. N., Lancaster, K. Z., Zhen, G., He, J., Gupta, M. K., Kong, Y., et al. (2015). 3D printed anatomical nerve regeneration pathways. Adv. Funct. Mater. 25, 6205-6217. doi:10.1002/adfm.201501760

Jones, I., Currie, L., and Martin, R. (2002). A guide to biological skin substitutes. $\mathrm{Br}$. J. Plast. Surg. 55, 185-193. doi:10.1054/bjps.2002.3800

Jordan, S. W., Haller, C. A., Sallach, R. E., Apkarian, R. P., Hanson, S. R., and Chaikof, E. L. (2007). The effect of a recombinant elastin-mimetic coating of an ePTFE prosthesis on acute thrombogenicity in a baboon arteriovenous shunt. Biomaterials 28, 1191-1197. doi:10.1016/j.biomaterials.2006.09.048

Jurga, M., Dainiak, M. B., Sarnowska, A., Jablonska, A., Tripathi, A., Plieva, F. M., et al. (2011). The performance of laminin-containing cryogel scaffolds in neural tissue regeneration. Biomaterials 32, 3423-3434. doi:10.1016/j.biomaterials. 2011.01.049

Karageorgiou, V., and Kaplan, D. (2005). Porosity of 3D biomaterial scaffolds and osteogenesis. Biomaterials 26, 5474-5491. doi:10.1016/j.biomaterials.2005. 02.002

Katsogiannis, K. A. G., Vladisavljević, G. T., and Georgiadou, S. (2016). Porous electrospun polycaprolactone fibers: effect of process parameters. J. Polym. Sci. B Polym. Phys. 54, 1878-1888. doi:10.3390/polym10070753

Kawabata, S., Kawai, K., Somamoto, S., Noda, K., Matsuura, Y., Nakamura, Y., et al. (2017). The development of a novel wound healing material, silk-elastin sponge. J. Biomater. Sci. Polym. Ed. 28, 2143-2153. doi:10.1080/09205063. 2017.1382829

Kim, I., Lee, S. S., Bae, S., Lee, H., and Hwang, N. S. (2018). Heparin functionalized injectable cryogel with rapid shape-recovery property for neovascularization. Biomacromolecules 19, 2257-2269. doi:10.1021/acs.biomac.8b00331

Koens, M., Faraj, K. A., Wismans, R. G., van der Vliet, J. A., Krasznai, A. G., Cuijpers, V. M., et al. (2010). Controlled fabrication of triple layered and molecularly defined collagen/elastin vascular grafts resembling the native blood vessel. Acta Biomater 6, 4666-4674. doi:10.1016/j.actbio.2010.06.038

Kowalczyk, T., Hnatuszko-Konka, K., Gerszberg, A., and Kononowicz, K. A. (2014). Elastin-like polypeptides as a promising family of geneticallyengineered protein based polymers. World J. Microbiol. Biotechnol 30, 2141-2152. doi:10.1007/s11274-014-1649-5

Krafts, K. P. (2010). Tissue repair: the hidden drama. Organogenesis 6, 225-233. doi:10.4161/org.6.4.12555

Kratochvil, M. J., Seymour, A. J., Li, T. L., Paşca, S. P., Kuo, C. J., Heilshorn, S., et al. (2019). Engineered materials for organoid systems. Nat. Rev. Mater. 4, 606-622. doi:10.1038/s41578-019-0129-9

Kubo, H., Shimizu, T., Yamato, M., Fujimoto, T., and Okano, T. (2007). Creation of myocardial tubes using cardiomyocyte sheets and an in vitro cell sheetwrapping device. Biomaterials 28, 3508-3516. doi:10.1016/j.biomaterials. 2007.04.016

Kumashiro, K. K., Ho, J. P., Niemczura, W. P., and Keeley, F. W. (2006). Cooperativity between the hydrophobic and cross-linking domains of elastin. J. Biol. Chem. 281, 23757-23765. doi:10.1074/jbc.M510833200

Kweon, H., Yoo, M., Park, I. K., Kim, T. H., Lee, H. C., Lee, H. S., et al. (2003). A novel degradable polycaprolactone networks for tissue engineering. Biomaterials 24, 801-808. doi:10.1016/s0142-9612(02)00370-8

Lampe, K. J., and Heilshorn, S. C. (2012). Building stem cell niches from the molecule up through engineered peptide materials. Neurosci. Lett. 519, 138-146. doi:10.1016/j.neulet.2012.01.042

Lao, U., Sun, M., Matsumoto, M., Mulchandani, A., and Chen, W. (2007). Genetic engineering of self-assembled protein hydrogel based on elastin-like sequences with metal binding functionality. Biomacromolecules 8, 3736-3739. doi:10. $1021 / \mathrm{bm} 700662 \mathrm{n}$

Le, D. H., T., and Sugawara-Narutaki, A. (2019). Elastin-like polypeptides as building motifs toward designing functional nanobiomaterials. Mol. Syst. Design Eng. 4, 545-565. doi:10.1039/C9ME00002J

Lee, K. M., Kim, J. H., Choi, E. S., Kim, E., Choi, S. K., and Jeon, W. B. (2019). RGDcontaining elastin-like polypeptide improves islet transplantation outcomes in diabetic mice. Acta Biomater 94, 351-360. doi:10.1016/j.actbio.2019.06.011

Lee, K. W., Stolz, D. B., and Wang, Y. (2011). Substantial expression of mature elastin in arterial constructs. Proc. Natl. Acad. Sci. U.S.A. 108, 2705. doi:10. 1073/pnas.1017834108

Leong, K. F., Cheah, C. M., and Chua, C. K. (2003). Solid freeform fabrication of three-dimensional scaffolds for engineering replacement tissues and organs. Biomaterials 24, 2363-2378. doi:10.1016/s0142-9612(03)00030-9
Lesavage, B. L., Suhar, N. A., Madl, C. M., and Heilshorn, S. C. (2018). Production of elastin-like protein hydrogels for encapsulation and immunostaining of cells in 3D. J. Vis. Exp. 2018, e57739. doi:10.3791/57739

Li, J., Wu, C., Chu, P. K., and Gelinsky, M. (2020). 3D printing of hydrogels: rational design strategies and emerging biomedical applications. Mater. Sci. Eng. R Rep. 140, 100543. doi:10.1016/j.mser.2020.100543

Li, Y., Rodríguez-Cabello, J. C., and Aparicio, C. (2017). Intrafibrillar mineralization of self-assembled elastin-like recombinamer fibrils. ACS. Appl. Mater. Interfaces 9, 5838-5846. doi:10.1021/acsami.6b15285

Liang, X., Qi, Y., Pan, Z., He, Y., Liu, X., Cui, S., et al. (2018). Design and preparation of quasi-spherical salt particles as water-soluble porogens to fabricate hydrophobic porous scaffolds for tissue engineering and tissue regeneration. Mater. Chem. Front. 2, 1539-1553. doi:10.1039/C8QM00152A

Lim, D., Nettles, D. L., Setton, L. A., and Chilkoti, A. (2008). In situ cross-linking of elastin-like polypeptide block copolymers for tissue repair. Biomacromolecules 9, 222-230. doi:10.1021/bm7007982

Lim, D. W., Nettles, D. L., Setton, L. A., and Chilkoti, A. (2007). Rapid cross-linking of elastin-like polypeptides with (hydroxymethyl)phosphines in aqueous solution. Biomacromolecules 8, 1463-1470. doi:10.1021/bm061059m

Lin, S., Sangaj, N., Razafiarison, T., Zhang, C., and Varghese, S. (2011). Influence of physical properties of biomaterials on cellular behavior. Pharm. Res. 28, 1422-1430. doi:10.1007/s11095-011-0378-9

Liu, X., Zhao, Y., Gao, J., Pawlyk, B., Starcher, B., Spencer, J. A., et al. (2004). Elastic fiber homeostasis requires lysyl oxidase-like 1 protein. Nat. Genet. 36, 178-182. doi:10.1038/ng1297

Luo, T., and Kiick, K. L. (2015). Noncovalent modulation of the inverse temperature transition and self-assembly of elastin-b-collagen-like peptide bioconjugates. J. Am. Chem. Soc. 137, 15362-15365. doi:10.1021/jacs.5b09941

Madl, C. M., Katz, L. M., and Heilshorn, S. C. (2018). Tuning bulk hydrogel degradation by simultaneous control of proteolytic cleavage kinetics and hydrogel network architecture. ACS Macro Lett. 7, 1302-1307. doi:10.1021/ acsmacrolett.8b00664

Mahara, A., Kiick, K. L., and Yamaoka, T. (2017). In vivo guided vascular regeneration with a non-porous elastin-like polypeptide hydrogel tubular scaffold. J. Biomed. Mater. Res. 105, 1746-1755. doi:10.1002/jbm.a.36018

Martín, L., Alonso, M., Girotti, A., Arias, F., Rodríguez-Cabello, J. C., and Rodríguez-Cabello, J.-C. (2009a). Synthesis and characterization of macroporous thermosensitive hydrogels from recombinant elastin-like polymers. Biomacromolecules 10, 3015-3022. doi:10.1021/bm900560a

Martín, L., Alonso, M., Möller, M., Rodríguez-Cabello, J.-C., and Mela, P. (2009b). $3 \mathrm{D}$ microstructuring of smart bioactive hydrogels based on recombinant elastin-like polymers. Soft Matter 5, 1591-1593.

Martín, L., Arias, F. J., Alonso, M., García-Arévalo, C., and Rodríguez-Cabello, J.-C. (2010). Rapid micropatterning by temperature-triggered reversible gelation of a recombinant smart elastin-like tetrablock-copolymer. Soft Matter 6, 1121-1124. doi:10.1039/B923684H

Martino, M., and Tamburro, A. M. (2001). Chemical synthesis of cross-linked poly(KGGVG), an elastin-like biopolymer. Biopolymers 59, 29-37. doi:10.1002/ 1097-0282(200107)59:1<29::AID-BIP1003>3.0.CO;2-F

Mastroianni, M., Ng, Z. Y., Goyal, R., Mallard, C., Farkash, E. A., Leonard, D. A., et al. (2018). Topical delivery of immunosuppression to prolong xenogeneic and allogeneic split-thickness skin graft survival. J. Burn Care Res. 39, 363-373. doi:10.1097/BCR.0000000000000597

Mbundi, L., Meikle, S. T., Busquets, R., Dowell, N. G., Cercignani, M., and Santin, M. (2018). Gadolinium tagged osteoprotegerin-mimicking peptide: a novel magnetic resonance imaging biospecific contrast agent for the inhibition of osteoclastogenesis and osteoclast activity. Nanomaterials 8, 399. doi:10.3390/ nano8060399

Mccusker, L. B., Liebau, F., and Engelhardt, G. (2003). Nomenclature of structural and compositional characteristics of ordered microporous and mesoporous materials with inorganic hosts: (IUPAC recommendations 2001). Microporous Mesoporous Mater. 58, 3-13. doi:10.1016/S1387-1811(02)00545-0

Mcdaniel, J. R., Radford, D., Chilkoti, A., and Chilkoti, A. (2013). A unified model for de novo design of elastin-like polypeptides with tunable inverse transition temperatures. Biomacromolecules 14, 2866-2872. doi:10.1021/bm4007166

McGuckin, H. M., and Sullivan, K. A. (1982). Lysyl oxidase: preparation and role in elastin biosynthesis. Methods Enzymol. 82, 637-650. doi:10.1016/00766879(82)82092-2 
Mchale, M. K., Setton, L. A., and Chilkoti, A. (2005). Synthesis and in vitro evaluation of enzymatically cross-linked elastin-like polypeptide gels for cartilaginous tissue repair. Tissue Eng. 11, 1768-1779. doi:10.1089/ten.2005. 11.1768

Mcmillan, R. A., and Conticello, V. P. (2000). Synthesis and characterization of elastin-mimetic protein gels derived from a well-defined polypeptide precursor. Macromolecules 33, 4809-4821. doi:10.1021/ma9921091

Mcnaught, A. D., and Wilkinson, A. (1997). IUPAC compendium of chemical terminology (Gold book). 2nd Edn. Cambridge, UK: Oxford Blackwell Scientific Publications.

Mecham, R. P. (1991). Elastin synthesis and fiber assembly. Ann. N. Y. Acad. Sci. 624, 137-146. doi:10.1111/j.1749-6632.1991.tb17013.x

Meddahi-Pellé, A., Legrand, A., Marcellan, A., Louedec, L., Letourneur, D., and Leibler, L. (2014). Organ repair, hemostasis, and in vivo bonding of medical devices by aqueous solutions of nanoparticles. Angew Chem. Int. Ed. Engl. 53, 6369-6373. doi:10.1002/anie.201401043

Melchels, F., Feijen, J., Grijpma, D. W., Grijpma, D., and , W. (2010). A review on stereolithography and its applications in biomedical engineering. Biomaterials 31, 6121-6130.doi:10.1016/j.biomaterials.2010.04.050

Memic, A., Colombani, T., Eggermont, L. J., Rezaeeyazdi, M., Steingold, J., Rogers, Z. J., et al. (2019). Latest advances in cryogel technology for biomedical applications. Adv. Therapeutics 2, 1800114. doi:10.1002/adtp.201800114

Meyer, D. E., and Chilkoti, A. (2004). Quantification of the effects of chain length and concentration on the thermal behavior of elastin-like polypeptides. Biomacromolecules 5, 846-851. doi:10.1021/bm034215n

Miao, M., Bellingham, C. M., Stahl, R. J., Sitarz, E. E., Lane, C. J., and Keeley, F. W. (2003). Sequence and structure determinants for the self-aggregation of recombinant polypeptides modeled after human elastin. J. Biol. Chem. 278, 48553-48562. doi:10.1074/jbc.M308465200

Miller, J. S., Kennedy, R. J., and Kemp, D. S. (2002). Solubilized, spaced polyalanines: a context-free system for determining amino acid alpha-helix propensities. J. Am. Chem. Soc. 124, 945-962. doi:10.1021/ja011726d

Misbah, M., Hamed, Q. L., Alonso, M., and Rodríguez-Cabello, J.-C. (2015). Evolution of amphiphilic elastin-like co-recombinamer morphologies from micelles to a lyotropic hydrogel. Polymer 81, 37-44. doi:10.1016/j.polymer. 2015.11.013

Misbah, M., Santos, M., Quintanilla, L., Günter, C., Alonso, M., Taubert, A., et al. (2017). Recombinant DNA technology and click chemistry: a powerful combination for generating a hybrid elastin-like-statherin hydrogel to control calcium phosphate mineralization. Beilstein J. Nanotechnol. 8, 772-783. doi:10.3762/bjnano.8.80

Mithieux, S. M., Aghaei-Ghareh-Bolagh, B., Yan, L., Kuppan, K. V., Wang, Y., Garces-Suarez, F., et al. (2018). Tropoelastin implants that accelerate wound repair. Adv. Health Mater. 7, e1701206. doi:10.1002/adhm.201701206

Mithieux, S. M., Rasko, J. E., and Weiss, A. S. (2004). Synthetic elastin hydrogels derived from massive elastic assemblies of self-organized human protein monomers. Biomaterials 25, 4921-4927. doi:10.1016/j.biomaterials.2004.01.055

Mithieux, S. M., and Weiss, A. S. (2005). "Elastin," in Advances in protein chemistry. Cambridge, MA: Academic Press, 437-461.

Mithieux, S. M., and Weiss, A. S. (2017). Design of an elastin-layered dermal regeneration template. Acta Biomater 52, 33-40. doi:10.1016/j.actbio.2016. 11.054

Mithieux, S., Wise, S. G., and Weiss, A. S. (2013). Tropoelastin--a multifaceted naturally smart material. Adv. Drug Deliv. Rev. 65, 421-428. doi:10.1016/j.addr. 2012.06.009

Mitragotri, S., and Lahann, J. (2009). Physical approaches to biomaterial design. Nat. Mater. 8, 15-23. doi:10.1038/nmat2344

Mitrousis, N., Fokina, A., and Shoichet, M. S. (2018). Biomaterials for cell transplantation. Nature Reviews Materials 3, 441-456. doi:10.1038/s41578018-0057-0

Muiznieks, L. D., and Keeley, F. W. (2013). Molecular assembly and mechanical properties of the extracellular matrix: a fibrous protein perspective. Biochim. Biophys. Acta. 1832, 866-875. doi:10.1016/j.bbadis.2012.11.022

Murphy, W. L., Dennis, R. G., Kileny, J. L., and Mooney, D. J. (2002). Salt fusion: an approach to improve pore interconnectivity within tissue engineering scaffolds. Tissue Eng. 8, 43-52. doi:10.1089/107632702753503045

Nagapudi, K., Brinkman, W. T., Thomas, B. S., Park, J. O., Srinivasarao, M., Wright, E., et al. (2005). Viscoelastic and mechanical behavior of recombinant protein elastomers. Biomaterials 26, 4695-4706. doi:10.1016/j.biomaterials. 2004.11.027

Nair, A., Thevenot, P., Dey, J., Shen, J., Sun, M. W., Yang, J., et al. (2010). Novel polymeric scaffolds using protein microbubbles as porogen and growth factor carriers. Tissue Eng. C Methods 16, 23-32. doi:10.1089/ten.TEC.2009.0094

Nair, D. P., Podgórski, M., Chatani, S., Gong, T., Xi, W., Fenoli, C. R., et al. (2014). The thiol-michael addition click reaction: a powerful and widely used tool in materials chemistry. Chem. Mater. 26, 724-744. doi:10.1021/cm402180t

Nair, L. S., and Laurencin, C., T. (2007). Biodegradable polymers as biomaterials. Prog. Polym. Sci. 32, 762-798. doi:10.1016/j.progpolymsci.2007.05.017

Najdanović, J., Rajković, J., and Najman, S. (2018). "Bioactive biomaterials: potential for application in bone regenerative medicine,"in Biomaterials in clinical practice: advances in clinical research and medical devices. Editors F. Zivic, S. Affatato, M. Trajanovic, M. Schnabelrauch, N. Grujovic, and K.L. Choy (Cham, Switzerland: Springer International Publishing)), 333-360.

Nasim, A., Jason, W., Nichol, X. Z., Chengdong, J., Sandeep, K., Ali, K., et al. (2010). Controlling the porosity and microarchitecture of hydrogels for tissue engineering. Tissue Eng. B Rev. 16, 371-383. doi:10.1089/ten.TEB. 2009.0639

Nettles, D. L., Kitaoka, K., Hanson, N. A., Flahiff, C. M., Mata, B. A., Hsu, E. W., et al. (2008). In situ crosslinking elastin-like polypeptide gels for application to articular cartilage repair in a goat osteochondral defect model. Tissue Eng. 14, 1133-1140. doi:10.1089/ten.tea.2007.0245

Noor, N., Shapira, A., Edri, R., Gal, I., Wertheim, L., and Dvir, T. (2019). 3D printing of personalized thick and perfusable cardiac patches and hearts. $A d v$. Sci. 6, 1900344. doi:10.1002/advs.201900344

Nosé, Y., Horiuchi, T., Malchesky, P. S., Smith, J. W., Matsubara, S., and Abe, Y. (2000). Therapeutic cryogel removal in autoimmune disease: what is cryogel? Ther. Apher. 4, 38-43. doi:10.1046/j.1526-0968.2000.00239.x

Offeddu, G. S., Mela, I., Jeggle, P., Henderson, R. M., Smoukov, S. K., Oyen, M., et al. (2017). Cartilage-like electrostatic stiffening of responsive cryogel scaffolds. Sci. Rep. 7, 42948. doi:10.1038/srep42948

Oh, S., Park, I. K., Kim, J. M., and Lee, J. H. (2007). In vitro and in vivo characteristics of PCL scaffolds with pore size gradient fabricated by a centrifugation method. Biomaterials 28, 1664-1671. doi:10.1016/j. biomaterials.2006.11.024

Paiva Dos Santos, B., Garbay, B., Pasqua, M., Chevron, E., Chinoy, Z., Cullin, C., et al. (2019). Production, purification and characterization of an elastin-like polypeptide containing the Ile-Lys-Val-Ala-Val (IKVAV) peptide for tissue engineering applications. J. Biotechnol 298, 35-44. doi:10.1016/j.jbiotec.2019. 04.010

Paoli, R., Bulwan, M., Castaño, O., Engel, E., Rodriguez-Cabello, J. C., HomsCorbera, A., et al. (2020). Layer-by-layer modification effects on a nanopore's inner surface of polycarbonate track-etched membranes. RSC Adv. 10, 35930-35940.

Paul, A., Stührenberg, M., Chen, S., Rhee, D., Lee, W. K., Odom, T. W., et al. (2017). Micro- and nano-patterned elastin-like polypeptide hydrogels for stem cell culture. Soft Matter 13, 5665-5675. doi:10.1039/c7sm00487g

Pescador, D., Ibáñez-Fonseca, A., Sánchez-Guijo, F., Briñón, J. G., Arias, F., Muntión, S., et al. (2017). Regeneration of hyaline cartilage promoted by xenogeneic mesenchymal stromal cells embedded within elastin-like recombinamer-based bioactive hydrogels. J. Mater. Sci. Mater. Med. 28, 115. doi:10.1007/s10856-017-5928-1

Petersen, W., Rahmanian-Schwarz, A., Werner, J. O., Schiefer, J., Rothenberger, J., Hübner, G., et al. (2016). The use of collagen-based matrices in the treatment of full-thickness wounds. Burns 42, 1257-1264. doi:10.1016/j.burns.2016.03.017

Pirayesh, A., Hoeksema, H., Richters, C., Verbelen, J., and Monstrey, S. (2015). Glyaderm $\left({ }^{\circledR}\right)$ dermal substitute: clinical application and long-term results in 55 patients. Burns 41, 132-144. doi:10.1016/j.burns.2014.05.013

Poocza, L., Cipriani, F., Alonso, M., and Rodríguez-Cabello, J. C. (2019). Hydrophobic cholesteryl moieties trigger substrate cell-membrane interaction of elastin-mimetic protein coatings in vitro. ACS Omega 4, 10818-10827. doi:10.1021/acsomega.9b00548

Pountos, I., Panteli, M., Lampropoulos, A., Jones, E., Calori, G., Giannoudis, P. V., et al. (2016). The role of peptides in bone healing and regeneration: a systematic review. BMC Med. 14, 103. doi:10.1186/s12916-016-0646-y

Putzu, M., Causa, F., Nele, V., De Torre, I., Rodriguez-Cabello, J., Netti, P. A., et al. (2016). Elastin-like-recombinamers multilayered nanofibrous scaffolds for 
cardiovascular applications. Biofabrication 8, 045009. doi:10.1088/1758-5090/ $8 / 4 / 045009$

Putzu, M., Causa, F., Parente, M., González de Torre, I., Rodríguez-Cabello, J. C., and Netti, P. A. (2019). Silk-ELR co-recombinamer covered stents obtained by electrospinning. Regen. Biomater 6, 21-28. doi:10.1093/rb/rby022

Qin, D., Xia, Y., and Whitesides, G. M. (2010). Soft lithography for micro- and nanoscale patterning. Nat. Protoc. 5, 491-502. doi:10.1038/nprot.2009.234

Raeisdasteh Hokmabad, V., Davaran, S., Ramazani, A., and Salehi, R. (2017). Design and fabrication of porous biodegradable scaffolds: a strategy for tissue engineering. J. Biomater. Sci. Polym. Ed. 28, 1797-1825. doi:10.1080/09205063. 2017.1354674

Raphel, J., Parisi-Amon, A., and Heilshorn, S. (2012). Photoreactive elastin-like proteins for use as versatile bioactive materials and surface coatings. J. Mater. Chem. 22, 19429-19437. doi:10.1039/C2JM31768K

Rauscher, S., Baud, S., Miao, M., Keeley, F. W., and Pomès, R. (2006). Proline and Glycine control protein self-organization into elastomeric or amyloid fibrils. Structure 14, 1667-1676. doi:10.1016/j.str.2006.09.008

Reddel, C. J., Cultrone, D., Rnjak-Kovacina, J., Weiss, A. S., and Burgess, J. K. (2013). Tropoelastin modulates TGF- $\beta 1$-induced expression of VEGF and CTGF in airway smooth muscle cells. Matrix Biol. 32, 407-413. doi:10.1016/ j.matbio.2013.04.003

Reichheld, S. E., Muiznieks, L. D., Stahl, R., Simonetti, K., Sharpe, S., and Keeley, F. W. (2014). Conformational transitions of the cross-linking domains of elastin during self-assembly. J. Biol. Chem. 289, 10057-10068. doi:10.1074/jbc.M113. 533893

Rey, D. F. V., and St-Pierre, J.-P. (2019). "Fabrication techniques of tissue engineering scaffolds," in Woodhead publishing series in biomaterials. Editors M. Mozafari, F. Sefat, and A. Atala (Cambridge, MA: Woodhead Publishing), 109-125.

Rnjak, J., Li, Z., Maitz, P. K., Wise, S. G., and Weiss, A. S. (2009). Primary human dermal fibroblast interactions with open weave three-dimensional scaffolds prepared from synthetic human elastin. Biomaterials 30, 6469-6477. doi:10. 1016/j.biomaterials.2009.08.017

Rnjak-Kovacina, J., Wise, S. G., Li, Z., Maitz, P., Young, C. J., Wang, Y., et al. (2011). Tailoring the porosity and pore size of electrospun synthetic human elastin scaffolds for dermal tissue engineering. Biomaterials 32, 6729-6736. doi:10. 1016/j.biomaterials.2011.05.065

Rnjak-Kovacina, J., and Weiss, A. S. (2013). "The role of elastin in wound healing and dermal substitute design," in Dermal replacements in general, burn, and plastic surgery: tissue engineering in clinical practice. Editors L.-P. Kamolz and D. B. Lumenta (Vienna, UK: Springer Vienna), 57-66.

Roberts, S., Dzuricky, M., and Chilkoti, A. (2015). Elastin-like polypeptides as models of intrinsically disordered proteins. FEBS Lett. 589, 2477-2486. doi:10. 1016/j.febslet.2015.08.029

Roberts, S., Harmon, T. S., Schaal, J. L., Miao, V., Li, K., Hunt, A., et al. (2018). Injectable tissue integrating networks from recombinant polypeptides with tunable order. Nat. Mater. 17, 1154-1163. doi:10.1038/s41563-018-0182-6

Rodríguez-Cabello, J.-C., Alonso, M., Díez, M. I., Caballero, M. I., and Herguedas, M. M. (1999). Structural investigation of the poly(pentapeptide) of elastin, poly(GVGVP), in the solid state. Macromol. Chem. Phys. 200, 1831-1838. doi:10.1002/(SICI)1521-3935(19990801)200:8<1831::AID-MACP1831>3.0. $\mathrm{CO} ; 2-\mathrm{V}$

Rodríguez-Cabello, J.-C., Ibáñez Fonseca, A., Alonso, M., Poocza, L., Cipriani, F., and Gonzalez De Torre, I. (2017). "Elastin-like polymers: properties, synthesis, and applications," in Encyclopedia of polymer science and technology (Hoboken, NJ: John Wiley \& Sons, Inc.), 1-36.

Rodríguez-Cabello, J.-C., Martín, L., Alonso, M., Arias, F. J., and Testera, A. M. (2009). "Recombinamers" as advanced materials for the post-oil age. Polymer 50, 5159-5169. doi:10.1016/j.polymer.2009.08.032

Rodríguez-Cabello, J. C., Girotti, A., Ribeiro, A., and Arias, F. J. (2012). "Synthesis of genetically engineered protein polymers (recombinamers) as an example of advanced self-assembled smart materials," in Nanotechnology in regenerative medicine: methods and protocols. Editors M. Navarro and J. A. Planell (Totowa, NJ: Humana Press), 17-38.

Romero, N., Tinker, D., Hyde, D., and Rucker, R. B. (1986). Role of plasma and serum proteases in the degradation of elastin. Arch. Biochem. Biophys. 244, 161-168. doi:10.1016/0003-9861(86)90105-0
Roy, T., Simon, J. L., Ricci, J. L., Rekow, E. D., Thompson, V. P., Parsons, J., et al. (2003). Performance of degradable composite bone repair products made via three-dimensional fabrication techniques. J. Biomed. Mater. Res. 66, 283-291. doi:10.1002/jbm.a.10582

Sabino, M. A., Loaiza, M., Dernowsek, J., Rezende, R., and Da Silva, J. V. L. (2017). Técnicas para La fabricación de andamios poliméricos con aplicaciones en ingeniería de tejidos (techniques for manufacturing polymer scaffolds with potential applications in tissue engineering). Revista Latinoamericana de Metalurgia y Materiales 37, 1-27.

Salinas-Fernández, S., Santos, M., Alonso, M., Quintanilla, L., and RodríguezCabello, J.-C. (2020). Genetically engineered elastin-like recombinamers with sequence-based molecular stabilization as advanced bioinks for 3D bioprinting. Appl. Mater. Today 18, 100500. doi:10.1016/j.apmt.2019.100500

Sallach, R. E., Cui, W., Wen, J., Martinez, A., Conticello, V., and Chaikof, E. L. (2009a). Elastin-mimetic protein polymers capable of physical and chemical crosslinking. Biomaterials 30, 409-422. doi:10.1016/j.biomaterials.2008.09.040

Sallach, R. E., Leisen, J., Caves, J. M., Fotovich, E., Apkarian, R. P., Conticello, V. P., et al. (2009b). A permanent change in protein mechanical responses can be produced by thermally-induced microdomain mixing. J. Biomater. Sci. Polym. Ed. 20, 1629-1644. doi:10.1163/156856208X386228

Sarker, M. D., Naghieh, S., Sharma, N. K., and Chen, X. (2018). 3D biofabrication of vascular networks for tissue regeneration: a report on recent advances. J. Pharm. Anal. 8, 277-296. doi:10.1016/j.jpha.2018.08.005

Savina, I. N., Ingavle, G. C., Cundy, A. B., and Mikhalovsky, S. V. (2016). A simple method for the production of large volume 3D macroporous hydrogels for advanced biotechnological, medical and environmental applications. Sci. Rep. 6, 21154. doi:10.1038/srep21154

Sayin, E., Rashid, R., Rodríguez-Cabello, J. C., Elsheikh, A., Baran, E., Hasirci, V., et al. (2017). Human adipose derived stem cells are superior to human osteoblasts (HOB) in bone tissue engineering on a collagen-fibroin-ELR blend. Bioact Mater. 2, 71-81. doi:10.1016/j.bioactmat.2017.04.001

Sengupta, D., and Heilshorn, S. C. (2010). Protein-engineered biomaterials: highly tunable tissue engineering scaffolds. Tissue Eng. B Rev 16, 285-293. doi:10.1089/ ten.teb.2009.0591

Seol, Y.-J., Kang, T.-Y., and Cho, D.-W. (2012). Solid freeform fabrication technology applied to tissue engineering with various biomaterials. Soft Matter 8, 1730-1735. doi:10.1039/C1SM06863F

Shahrokhi, S., Arno, A., and Jeschke, M. G. (2014). The use of dermal substitutes in burn surgery: acute phase. Wound Repair Regen. 22, 14-22. doi:10.1111/wrr. 12119

Sheikh, Z., Hamdan, N., Ikeda, Y., Grynpas, M., Ganss, B., and Glogauer, M. (2017). Natural graft tissues and synthetic biomaterials for periodontal and alveolar bone reconstructive applications: a review. Biomater. Res. 21, 9. doi:10. 1186/s40824-017-0095-5

Sherratt, M. J. (2009). Tissue elasticity and the ageing elastic fibre. Age 31, 305-325. doi:10.1007/s11357-009-9103-6

Shirzaei Sani, E., Portillo-Lara, R., Spencer, A., Yu, W., Geilich, B. M., Noshadi, I., et al. (2018). Engineering adhesive and antimicrobial hyaluronic acid/elastinlike polypeptide hybrid hydrogels for tissue engineering applications. ACS Biomater. Sci. Eng. 4, 2528-2540. doi:10.1021/acsbiomaterials.8b00408

Shivalkar, S., and Singh, S. (2017). Solid freeform techniques application in bone tissue engineering for scaffold fabrication. Tissue Eng. Regen. Med. 14, 187-200. doi:10.1007/s13770-016-0002-5

Shuturminska, K., Tarakina, N. V., Azevedo, H. S., Bushby, A. J., Mata, A., Anderson, P., et al. (2017). Elastin-like protein, with statherin derived peptide, controls fluorapatite formation and morphology. Front. Physiol. 8, 368. doi:10.3389/fphys.2017.00368

Siegel, R. C., Pinnell, S. R., and Martin, G. R. (1970). Cross-linking of collagen and elastin. Properties of lysyl oxidase. Biochemistry 9, 4486-4492. doi:10.1021/ bi00825a004

Sieminski, A. L., Hebbel, R. P., and Gooch, K. J. (2005). Improved microvascular network in vitro by human blood outgrowth endothelial cells relative to vesselderived endothelial cells. Tissue Eng. 11, 1332-1345. doi:10.1089/ten.2005.11. 1332

Song, R., Murphy, M., Li, C., Ting, K., Soo, C., and Zheng, Z. (2018). Current development of biodegradable polymeric materials for biomedical applications. Drug Des. Devel. Ther. 12, 3117-3145. doi:10.2147/DDDT.S165440 
Staubli, S., Cerino, G., Gonzalez De Torre, I., Alonso, M., Oertli, D., Eckstein, F., et al. (2017). Control of angiogenesis and host response by modulating the cell adhesion properties of an Elastin-Like Recombinamer-based hydrogel. Biomaterials 135, 30-41. doi:10.1016/j.biomaterials.2017.04.047

Straley, K. S., and Heilshorn, S. C. (2009). Dynamic, 3D-pattern formation within enzyme-responsive hydrogels. Adv. Mater. 21, 4148-4152. doi:10.1002/adma. 200901865

Swanson, W. B., and Ma, P. X. (2020). "Textured and porous biomaterials," in Biomaterials science. Editors W. R. Wagner, S. E. Sakiyama-Elbert, G. Zhang, and M. J. Yaszemski. 4th Edn. (Cambridge, MA: Academic Press), 601-622.

Testa, U., Pannitteri, G., and Condorelli, G. L. (2008). Vascular endothelial growth factors in cardiovascular medicine. J. Cardiovasc. Med. 9, 1190-1221. doi:10. 2459/JCM.0b013e3283117d37

Testera, A. M., Girotti, A., De Torre, I., Quintanilla, L., Santos, M., Alonso, M., et al. (2015). Biocompatible elastin-like click gels: design, synthesis and characterization. J. Mater. Sci. Mater. Med. 26, 105. doi:10.1007/s10856-015-5435-1

Tjin, M., S., Low, P., and Fong, E. (2014). Recombinant elastomeric protein biopolymers: progress and prospects. Polym. J. 46, 444-451. doi:10.1038/pj. 2014.65

Tsiapalis, D., De Pieri, A., Biggs, M., Pandit, A., and Zeugolis, D. I. (2017). Biomimetic bioactive biomaterials: the next generation of implantable devices. ACS Biomater. Sci. Eng. 3, 1172-1174. doi:10.1021/acsbiomaterials. $7 \mathrm{~b} 00372$

Tu, Y., Mithieux, S. M., Annabi, N., Boughton, E. A., and Weiss, A. S. (2010). Synthetic elastin hydrogels that are coblended with heparin display substantial swelling, increased porosity, and improved cell penetration. J. Biomed. Mater. Res. 95, 1215-1222. doi:10.1002/jbm.a.32950

Urry, D. W., Gowda, D. C., Parker, T. M., Luan, C. H., Reid, M. C., Harris, C. M., et al. (1992). Hydrophobicity scale for proteins based on inverse temperature transitions. Biopolymers 32, 1243-1250. doi:10.1002/bip.360320913

Urry, D. W., and Pattanaik, A. (1997). Elastic protein-based materials in tissue reconstruction. Ann. N. Y. Acad. Sci. 831, 32-46. doi:10.1111/j.1749-6632.1997. tb52182.x

Urry, D. W., Jaggard, J., Harris, R., Dean, Chang, D. K., and Prasad, K., U. (1990). "The poly(nonapeptide) of elastin: a new elastomeric polypeptide biomaterial," in Progress in biomedical polymers. Editors C.G. GebeleinR.L. Dunn (Boston, MA: Springer US), 171-178.

Vasconcelos, A., Gomes, A. C., and Cavaco-Paulo, A. (2012). Novel silk fibroin/ elastin wound dressings. Acta Biomater 8, 3049-3060. doi:10.1016/j.actbio. 2012.04.035

Vijayavenkataraman, S., Zhang, S., Thaharah, S., Sriram, G., Lu, W. F., and Fuh, J. Y. H. (2018). Electrohydrodynamic jet 3D printed nerve guide conduits (NGCs) for peripheral nerve injury repair. Polymers 10, 753. doi:10.3390/ polym 10070753

Vrhovski, B., Jensen, S., and Weiss, A. S. (1997). Coacervation characteristics of recombinant human tropoelastin. Eur. J. Biochem. 250, 92-98. doi:10.1111/j. 1432-1033.1997.00092.x

Vrhovski, B., and Weiss, A. S. (1998). Biochemistry of tropoelastin. Eur. J. Biochem. 258, 1-18. doi:10.1046/j.1432-1327.1998.2580001.x

Wachi, H., Sato, F., Murata, H., Nakazawa, J., Starcher, B. C., and Seyama, Y. (2005). Development of a new in vitro model of elastic fiber assembly in human pigmented epithelial cells. Clin. Biochem. 38, 643-653. doi:10.1016/j. clinbiochem.2005.04.006

Wang, C., Liu, Y., Fan, Y., and Li, X. (2017). The use of bioactive peptides to modify materials for bone tissue repair. Regen. Biomater 4, 191-206. doi:10.1093/rb/ rbx011

Wang, H., Cai, L., Paul, A., Enejder, A., and Heilshorn, S. C. (2014). Hybrid elastinlike polypeptide-polyethylene glycol (ELP-PEG) hydrogels with improved transparency and independent control of matrix mechanics and cell ligand density. Biomacromolecules 15, 3421-3428. doi:10.1021/bm500969d

Wang, Y., Mithieux, S. M., Kong, Y., Wang, X. Q., Chong, C., Fathi, A., et al. (2015). Tropoelastin incorporation into a dermal regeneration template promotes wound angiogenesis. Adv. Health. Mater. 4, 577-584. doi:10.1002/adhm. 201400571

Wen, Q., Mithieux, S. M., and Weiss, A. S. (2020). Elastin biomaterials in dermal repair. Trends Biotechnol. 38, 280-291. doi:10.1016/j.tibtech.2019.08.005

Whang, K., Healy, K. E., Elenz, D. R., Nam, E. K., Tsai, D. C., Thomas, C. H., et al. (1999). Engineering bone regeneration with bioabsorbable scaffolds with novel microarchitecture. Tissue Eng. 5, 35-51. doi:10.1089/ten.1999.5.35

Wise, S. G., Yeo, G. C., Hiob, M. A., Rnjak-Kovacina, J., Kaplan, D. L., Ng, M. K., et al. (2014). Tropoelastin: a versatile, bioactive assembly module. Acta Biomater 10, 1532-1541. doi:10.1016/j.actbio.2013.08.003

Wong, R., Alam, N., Mcgrouther, A. D., and Wong, J. K. (2015). Tendon grafts: their natural history, biology and future development. J. Hand Surg. Eur. 40, 669-681. doi:10.1177/1753193415595176

Woodhouse, K. A., Klement, P., Chen, V., Gorbet, M. B., Keeley, F. W., Stahl, R., et al. (2004). Investigation of recombinant human elastin polypeptides as nonthrombogenic coatings. Biomaterials 25, 4543-4553. doi:10.1016/j.biomaterials. 2003.11.043

Wu, J., and Hong, Y. (2016). Enhancing cell infiltration of electrospun fibrous scaffolds in tissue regeneration. Bioact. Mater. 1, 56-64. doi:10.1016/j. bioactmat.2016.07.001

Yang, S., Leong, K. F., Du, Z., and Chua, C. K. (2001). The design of scaffolds for use in tissue engineering. Part I. Traditional factors. Tissue Eng. 7, 679-689. doi:10. 1089/107632701753337645

Yao, D., Dong, S., Lu, Q., Hu, X., Kaplan, D. L., Zhang, B., et al. (2012). Salt-leached silk scaffolds with tunable mechanical properties. Biomacromolecules 13, 3723-3729. doi:10.1021/bm301197h

Yeo, G. C., and Weiss, A. S. (2019). Soluble matrix protein is a potent modulator of mesenchymal stem cell performance. Proc. Natl. Acad. Sci. Unit. States Am. 116, 2042. doi:10.1073/pnas. 1812951116

Yeo, G. C., Keeley, F. W., and Weiss, A. S. (2011). Coacervation of tropoelastin. Adv. Colloid Interface Sci. 167, 94-103. doi:10.1016/j.cis.2010.10.003

Zhang, Y., Wang, C., Jiang, W., Zuo, W., and Han, G. (2017). Influence of stage cooling method on pore architecture of biomimetic alginate scaffolds. Sci. Rep. 7, 16150. doi:10.1038/s41598-017-16024-x

Zhang, Y. N., Avery, R. K., Vallmajo-Martin, Q., Assmann, A., Vegh, A., Memic, A., et al. (2015). A highly elastic and rapidly crosslinkable elastin-like polypeptidebased hydrogel for biomedical applications. Adv. Funct. Mater. 25, 4814-4826. doi:10.1002/adfm.201501489

Zhao, Y., Cao, X., and Jiang, L. (2007). Bio-mimic multichannel microtubes by a facile method. J. Am. Chem. Soc. 129, 764-765. doi:10.1021/ja068165g

Zhou, J., He, W., Luo, G., and Wu, J. (2013). Fundamental immunology of skin transplantation and key strategies for tolerance induction. Arch. Immunol. Ther. Exp. 61, 397-405. doi:10.1007/s00005-013-0233-2

Zhou, Y., Zhou, Y., Gao, L., Wu, C., and Chang, J. (2018). Synthesis of artificial dental enamel by an elastin-like polypeptide assisted biomimetic approach. J. Mater. Chem. B 6, 844-853. doi:10.1039/c7tb02576a

Zhu, D., Wang, H., Trinh, P., Heilshorn, S. C., and Yang, F. (2017). Elastin-like protein-hyaluronic acid (ELP-HA) hydrogels with decoupled mechanical and biochemical cues for cartilage regeneration. Biomaterials 127, 132-140. doi:10. 1016/j.biomaterials.2017.02.010

Conflict of Interest: The authors declare that the research was conducted in the absence of any commercial or financial relationships that could be construed as a potential conflict of interest.

Copyright (๑ 2021 Mbundi, González-Pérez, González-Pérez, Juanes-Gusano and Rodriguez-Cabello. This is an open-access article distributed under the terms of the Creative Commons Attribution License (CC BY). The use, distribution or reproduction in other forums is permitted, provided the original author(s) and the copyright owner(s) are credited and that the original publication in this journal is cited, in accordance with accepted academic practice. No use, distribution or reproduction is permitted which does not comply with these terms. 